Portland State University

PDXScholar

1-27-1995

\title{
Memory Deficit Compensation Among Survivors of Traumatic Brain Injury
}

Hugo Maynard

Portland State University

Follow this and additional works at: https://pdxscholar.library.pdx.edu/open_access_etds

Part of the Psychology Commons

Let us know how access to this document benefits you.

\section{Recommended Citation}

Maynard, Hugo, "Memory Deficit Compensation Among Survivors of Traumatic Brain Injury" (1995).

Dissertations and Theses. Paper 4871.

https://doi.org/10.15760/etd.6747

This Thesis is brought to you for free and open access. It has been accepted for inclusion in Dissertations and Theses by an authorized administrator of PDXScholar. Please contact us if we can make this document more accessible: pdxscholar@pdx.edu. 
The abstract and thesis of Nancy Ann Carney for the Master of Science in Psychology were presented on January 27, 1995, and accepted by the thesis committee and department.

COMMITTEE APPROVALS:

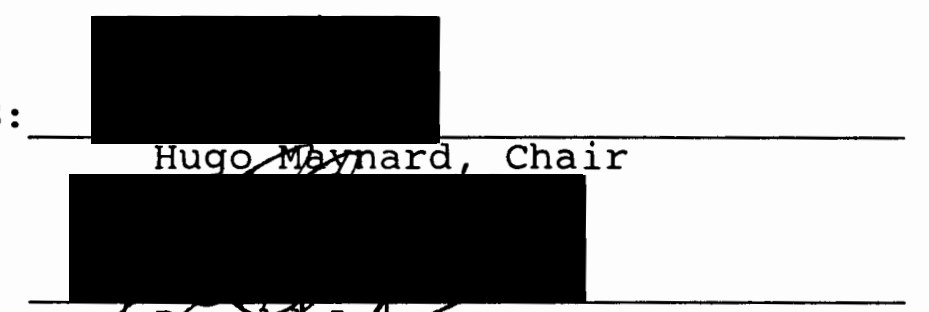

Bonatughe

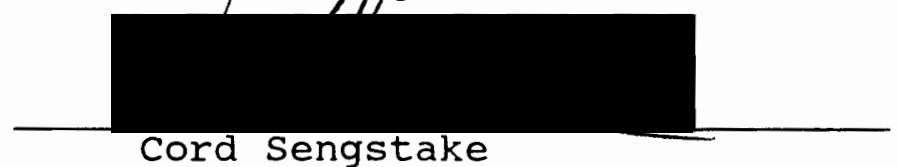

cord Sengstake

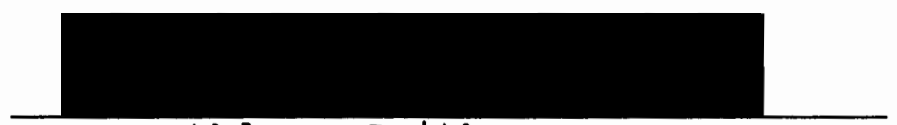

Cathleen smith

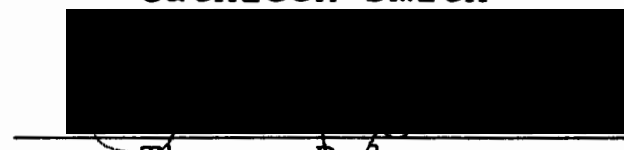

Thomas dolan

Representative of the office of Graduate studies

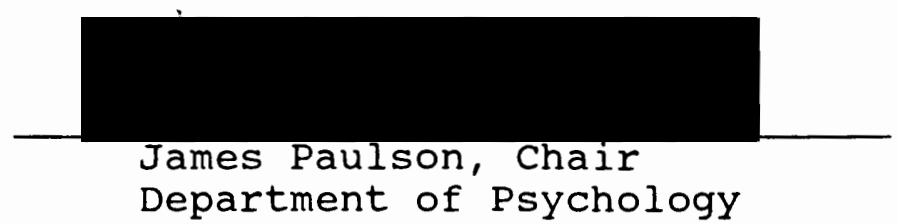

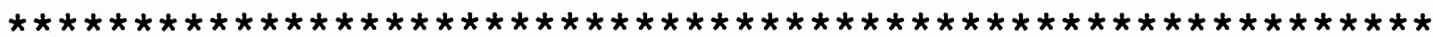

ACCEPTED FOR PORTLAND STATE UNIVERSITY BY THE LIBRARY

by

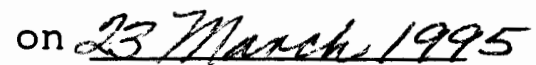




\section{ABSTRACT}

An abstract of the thesis of Nancy Ann Carney for the Master of Science in Psychology presented January 27, 1995.

Title: Memory Deficit Compensation Among Survivors of Traumatic Brain Injury

Memory impairment is an outcome of Traumatic Brain Injury (TBI), and associated with lower levels of postmorbid adjustment. This research isolated the memory impairment of retrieval deficit, and examined the efficacy of cues and mnemonics in remediating the impairment.

Thirty-three male and female TBI survivors, 18 to 71 years old, were pre-tested for attention (COPY), shortterm memory (SD), long-term memory (LD) and recognition memory (RS) employing the Rey Osterrieth Complex Figure Test (CFT), and subtest. Sixteen subjects demonstrating a retrieval deficit were administered the post-test, with even random assignment into four treatment conditions: a control group (CONTROL), a group administered cues (CUES), a group administered mnemonics (MNEM), and a group administered mnemonics and cues $(\mathrm{BOTH})(\underline{\mathrm{n}}=4)$.

A MANOVA revealed a significant effect of TRIAL 
( $\mathrm{p} \leq .05)$, no significant effect of TREATMENT, and no interaction. A power analysis indicated the lack of TREATMENT effect could be the result of sample size.

Post-hoc $\underline{t}$ tests revealed a difference across TRIAL for $S D$ and $L D$ in the two experimental conditions which utilized mnemonics. The sample was divided into two groups according to subjects' level of functioning (HIGH and LOW). A MANOVA showed main effects for LEVEL for SD and RS, for TRIAL for SD, LD, and RS, and a LEVEL by TRIAL interaction for COPY $(\underline{p}<.05)$. HIGH scored higher than LOW across trials on SD and RS. Post-test scores were higher than pre-test scores for both HIGH and LOW for SD, LD, and RS. LOW scored higher than HIGH on posttest copy scores.

Researchers concluded that (1) distraction resulting from the research design may have contributed to the lack of effect of TREATMENT, (2) mnemonics may be a more effective aid for recall than cues, (3) repeated exposure aided recall, (4) high cognitive functioning subjects performed better than low in tasks of short term memory and visual cues, but the groups were equalized in tasks of long term memory and repeated exposure. 
Qualitative information such as demographics and observations made during data collection were considered in presenting explanations for results, and suggestions for future research. 
MEMORY DEFICIT COMPENSATION AMONG SURVIVORS

OF TRAUMATIC BRAIN INJURY

by

NANCY ANN CARNEY

A thesis submitted in partial fulfillment of the requirements for the degree of

MASTER OF SCIENCE
in
PSYCHOLOGY

Portland State University

1995 
Retrieval

Memory Deficit Compensation Among Survivors of Traumatic Brain Injury

Traumatic Brain Injury (TBI)

Head injury is defined as "a traumatic insult to the brain capable of producing physical, intellectual, emotional, social, and vocational changes (National Head Injury Foundation, 1985)." The incidence of traumatic brain injury (TBI) in the United States has been estimated to be 200 per 100,000 population (Klonoff, Snow, \& Costa, 1986; Wehman et al., 1989). Recent developments in medical technology have increased the TBI survival rate (Brotherton, Thomas, Wisotzek, \& Milan, 1988; Cole, Cope, \& Cervelli, 1985; Elsass \& Kinsella, 1987; Godfrey, Knight, Marsh, Moroney, \& Bishara, 1989; Klonoff, Snow, \& Costa, 1986; Wehman et al., 1989). It is estimated that 15 years ago, one in ten TBI victims survived the trauma. Today, one in ten does not survive (Kraus, 1984). However, while medicine has developed the ability to save these lives, it cannot yet restore them all to normal functioning.

Variables such as injury site and size, length of time in coma, nature of pathology, as well as age, gender, and psychosocial history, affect the course and degree of the survivors' postmorbid recovery (Lezak, 
1983; Sohlberg \& Mateer, 1989).

While some research indicates deficits may be resolved within the first 3 months (Levin et al., 1987), other studies show that even with minor head trauma, deficits persist beyond 6 months (Bohnen, Jolles, \& Twijnstra, 1992). Varying degrees of physical, cognitive and behavioral deficits may persist for life (Lezak, 1983; Ridley, 1989).

over $60 \%$ of TBI victims are males under the age of 35 years (Wehman et al., 1989). The majority are adolescents and young adults (Elsass \& Kinsella, 1987). Few recover the ability to return to work (Wehman et al., 1989). The consequence of increased TBI survival rate without adequate rehabilitation is a rapidly growing population of people dependent upon family and social systems (Oregon Head Injury Foundation, 1994). Because little is known about restoring TBI survivors to normal functioning, they often are directed to hospitals, group homes, treatment plans and rehabilitation programs designed for populations with very different problems such as mental illness or mental retardation (Oregon Head Injury Foundation, 1994) . TBI and Memory Deficits

Physical and functional disabilities may occur at 
the time the brain damage is sustained; however, the most significant negative outcomes are psychosocial and psychological, often resulting in the development of secondary problems in family and behavior (Cole, Cope, \& Cervelli, 1985).

Memory impairment is a common outcome of TBI, and is associated with poor adjustment (Glasgow, Zeiss, \& Lewinsohn, 1977). Seventy percent of TBI survivors experience memory deficits beyond a year post-trauma (Sohlberg \& Mateer, 1989). While some survivors experience retrograde amnesia (loss of memory of events prior to trauma), the more common amnesia is for posttraumatic events (Sohlberg \& Mateer, 1989). Without the ability to acquire and refer to new information, survivors are rendered less capable of adapting to new people, restrictions, and environments. Rehabilitation

Currently, rehabilitation methods fall into two broad categories, reductionist and dynamic (Trexler, 1987). The reductionist approach uses performance scores on neuropsychologic tests to diagnose the deficit(s), and relies on practice or repetition to restore the function(s). The therapeutic focus is on physical, occupational, and speech therapy (Brotherton, Thomas, 
Wisotzek, \& Milan, 1988). However, the efficacy of traditional, reductionist rehabilitation relies on functional recall (Leland, Lewis, Hinman, \& Carrillo, 1988). Without the ability to consolidate new information, practice will not increase the ability to recall (Glisky \& Schacter, 1986; Godfrey \& Knight, 1985; Prigatano et al., 1984). The circumstances under which practice increases recall are of particular interest in determining if and when practice-based rehabilitation should be used.

The dynamic rehabilitation approach places a low reliance on absolute neuropsychologic test performance, and an emphasis on individual programs which are plastic and respond to the change and growth of the individual.

Before considering the efficacy of treatment approaches in the remediation of memory pathology, the body of knowledge and theory about nonpathological memory will be examined.

Memory Theory

Traditional Model of Memory. The traditional temporally-based model (Squire, 1975) describes memory in three stages. Sensory memory is available immediately after presentation of the stimulus, and fades rapidly over a period of seconds. Short term memory implies 
information is maintained, without permanent storage, for recall and use relatively soon after presentation of the stimulus. Long term memory refers to information which is stored and retrieved for use after minutes, days or years. The theory maintains that retention of long term memory is permanent. The model was expanded to include consolidation as a process which transfers information from short to long term memory.

Single vs. Multiple Memory system Models. An outcome of memory research has been the question: Is memory one system with multiple components, or is it several separate systems (Schacter, 1992)? If memory is a function of one system, then injury might affect all memory processes. However, if it is a function of multiple systems, injury may impair some processes and leave others intact. Therefore, the question holds important clinical implications for head injury research. In pursuit of the answer, many useful models have been created or elaborated, and subsequent research has been generated. One distinction holds that one kind of information retention, implicit memory, occurs nonconsciously, while another kind, explicit memory, is a function of active work on information (Bowers \& Schacter, 1990; Schacter, 1992). Priming effects, the 
phenomenon of stimulating recall without the individual's awareness through presentation of bits of information, is considered evidence for the existence of implicit memory (Tulving \& Schacter, 1990; Tulving, Hayman, \& Macdonald, 1991; Schacter, 1992). Priming, or cuing, is one strategy used in TBI rehabilitation (Lezak, 1983).

A second model distinguishes between knowledge of word meanings, or semantic memory, and recollection of time- and place-specific experiences, or episodic memory (Sohlberg \& Mateer, 1989). A third distinguishes between automatic behavior, or procedural memory, and the ability to explicitly report, or declarative memory (Sohlberg \& Mateer, 1989).

From another perspective, information retention is seen to be a function of depth of processing. The greater the depth, the greater the degree of semantic or cognitive analysis and subsequent retention (Craik \& Lockhart, 1972). The use of mnemonic strategies, repetition of bits of information, is believed to enhance depth of processing, and is another technique of TBI rehabilitation (Lezak, 1983).

Experimental results demonstrating use of the theorized levels of memory have been used as evidence in the continuing debate about single vs. multiple memory 
systems.

Information-Processing Model of Memory. Memory as an information-processing system consists of components of attention, encoding, storage, consolidation, and retrieval (Walker, 1976). It is conceptualized as a system of highly integrated and interdependent parts which process information at different levels (Cermak, 1982; Craik \& Lockhart, 1972). Sohlberg \& Mateer's (1989) elaboration of the components is as follows: Attention involves alertness and arousal. It is the capacity to hold information in a temporary store while mental operations are performed. Encoding refers to the level of analysis performed on material to be remembered. Storage is the transfer of information to a form or location in the brain for permanent storage or access. Consolidation is the process of integrating new memories into an existing schema. Retrieval is the search for or activation of memories and monitoring of the accuracy and appropriateness of memories pulled from storage. (p. 139)

Application of Models of Memory in Traumatic Brain Injury Research

The preceding memory models represent three 
approaches to the study of normal memory, and may be considered for their efficacy in providing a framework for memory pathology research.

Traditional. The traditional, linear model provides useful initial diagnostic criteria. A patient presenting low immediate memory, but intact recall after a 30-minute delay, may be experiencing attention or visual deficits rather than memory problems. However, by definition, short and long term memory are distinguished by rate of decay, capacity of storage, and type of encoding, and these distinctions do not always remain consistent under experimentation (Sohlberg \& Mateer, 1989). Furthermore, the simplicity of the model does not lend itself to diagnosis of complex cognitive breakdowns typical of TBI. Dichotomous. The dichotomous models outlined earlier (explicit vs. implicit, semantic vs. episodic, procedural vs. declarative) have been used to generate research with TBI survivors. Individuals presenting below normal explicit memory demonstrated near normal implicit memory on tasks involving priming or cuing (Bowers \& Schacter, 1990; Tulving \& Schacter, 1990). other studies demonstrated that individuals with intact semantic memory presented below normal episodic memory, and individuals with impaired declarative memory could 
automatically follow procedures they didn't remember learning (Sohlberg \& Mateer, 1989). Schacter and colleagues have been actively researching the question of single vs. multiple systems, utilizing both normal and memory deficit subjects (Bowers \& Schacter, 1990; Schacter, 1992; Tulving \& Schacter, 1990). However, as stated earlier, their research indicates that, without the fundamental ability to retain new information, the tool most widely used in rehabilitation, practice and repetition, will not increase recall (Glisky \& Schacter, 1986). So the question remains, how can the dichotomous models being generated be used to remediate memory problems?

Information Processing. Using the information processing model of memory as a guide, sohlberg and Mateer (1989) responded to Glisky and Schacter's assertion that practice does not increase recall in TBI survivors. They pointed out that treatment conditions in the cited studies exercised only the retrieval component of memory. They asserted that cognitive functioning can be improved with rehabilitation that targets specific processes defined by the information processing model. They noted that subsequent research using the model to distinguish deficits, and using practice to remediate, 
has demonstrated restoration (Mateer \& Sohlberg, 1988). Their dynamic (as opposed to reductionist) rehabilitation method assumes that different cognitive areas can be treated individually and can be directly retrained or corrected. The first step is to accurately identify the impaired process or processes.

Diagnostic Use of the Information Processing Model

A theoretical framework for identifying specific neurologic impairments in terms of the information processing model was defined by Sohlberg and Mateer (1989). They classified four types of deficits (attention, encoding, storage, and retrieval) and associated them with expected behaviors and test performances:

Memory Problems Secondary to Attention Deficits - . some individuals do have difficulty with focused, sustained, selective, alternating, and divided attention. The problems prohibit the effective registration of information for further information processing or subsequent recall. Memory Problems Secondary to Encoding Deficits - a patient with perceptual deficits may have difficulty reproducing or even recognizing visually presented designs but may not have a memory deficit 
Retrieval

per se. - Their understanding, organization, and categorization of material to be remembered is reduced, and attempts at subsequent recall of information are diminished.

\section{Memory Problems Related to storage}

Patients with storage impairments often have normal immediate and short-term memory. Their long-term memory is seriously impaired. Memory Problems Secondary to Retrieval Deficits - . the information is stored somewhere in the patient's nervous system but cannot be retrieved. Such patients may have intact recognition abilities. (p. 146)

Meyers, Meyers, and Lange (1993, unpublished) hypothesized that the sohlberg and Mateer taxonomy could be used to identify specific deficits using tests of immediate recall, short term recall, long term recall, and recognition. They suggested that people with attention, encoding, storage, and retrieval deficits would demonstrate different patterns of performance across these four tests. The Benton Visual Retention Test (BVRT) was used to measure immediate memory span and attention deficit (Lezak, 1983). The Rey Osterrieth Complex Figure Test (CFT) was used to measure short-term 
recall at the 3-minute drawing, and long-term recall at the 30-minute drawing (Lezak, 1983). The CFT Recognition Subtest (RS), a series of drawings which serve as cues to recall the CFT, was used to measure recognition (Meyers \& Meyers, 1992). Of the 48 head injured subjects tested, 11 demonstrated an attention deficit pattern, 8 an encoding deficit pattern, 5 a storage deficit pattern, and 21 a retrieval deficit pattern. Application of Diagnostic Results

Having established that patterns can be demonstrated for deficits in areas defined by the information processing model, Meyers et al. (1993, unpublished) suggested that different treatment approaches for deficit remediation could be used with individuals expressing different patterns. For instance, individuals with retrieval deficit appear to be aided in recall by cues, as demonstrated by the increase in their score for the CFT Recognition subtest. Cues, then, might be an effective strategy for rehabilitation of retrieval deficit individuals.

Cues, partial bits of information (Sohlberg \& Mateer, 1989), are a form of compensatory technique; an external memory aid. Luria (1963) promoted the use of cues to restore organized recall. Studies have 
demonstrated that normal memory can be enhanced by cuing (Craik \& Watkins, 1973).

Another form of compensatory technique, internal memory aids, includes mnemonic strategies such as rehearsing information or using visual imagery. As stated earlier, mnemonic devices are thought to increase depth of processing. Some research has demonstrated increased recall among head trauma patients through use of mnemonic techniques (Lewinsohn, Danaher, \& Kikel, 1977). However, strategies did not generalize (Sohlberg \& Mateer, 1989), the effect on recall did not persist at 1 week (Lewinsohn, Danaher, \& Kikel, 1977), and recall for patients with global amnesia did not improve (Jones, 1974). Other variables yet unidentified may affect the relationship between mnemonics and recall, and should be targeted in TBI research.

\section{Summary}

The following questions present themselves as important precursors to TBI research:

1) Multiple systems of Memory. If memory is a function of multiple systems, what are they? How can they be differentially tested? How are they interdependent? How can impairments in one system be distinguished from those in another? 
2) Practice. It has been demonstrated that without the capacity to retrieve, practice will not enhance recall. on the other hand, subjects seem to respond to practice when it is applied to specific memory processes. When does practice work, and when is it a waste of time?

3) Compensation Techniques. Under what circumstances will cues be most useful; when will mnemonics be most useful? What is the "survivor profile" most likely to respond to cues or mnemonics? Assuming memory is composed of multiple systems, to which system deficits should cues be applied; should mnemonics be applied?

\section{The Current Research}

The purpose of this research project was to investigate the possible effect of the external aid of cues and the internal aid of mnemonics on recall for head-injured individuals who have demonstrated a retrieval deficit.

subjects were tested to obtain measures of attention (COPY), short-term recall (SD), long-term recall (LD), and recognition (RS). Those who demonstrated a retrieval deficit pattern (retrieval deficit is operationally defined in the Method section) were included in the study, and their scores recorded as pre-test scores. They then were tested a second time under one of four 
conditions: no memory aids, cues, mnemonics, or both cues and mnemonics. It was expected that, in retrieval deficit pattern subjects, cuing would increase the scores for their short- and long-term recall from pre-test to post-test; that mnemonics would not increase the scores; and that scores for the group that received both cues and mnemonics would be the same as scores for the group that received only cues, further validating that mnemonics would not enhance recall. Specific hypotheses were:

a) For the CUES group, the SD and LD scores were expected to increase significantly from PRETEST to POST-TEST.

b) For the CUES group, the POST-TEST SD and LD scores were expected to be significantly higher than the same scores for the CONTROL and MNEM groups.

c) None of the test scores for CONTROL was expected to change significantly from PRE-TEST to POST-TEST.

d) Scores for MNEM were not expected to change significantly from PRE-TEST to POST-TEST.

e) POST-TEST SD and LD scores for BOTH were not expected to be significantly different from those for CUES. 
Retrieval

Method

\section{Subjects}

The Family Head Injury Support Network in Portland, Oregon sponsors support-group meetings attended by TBI survivors and their families. The support Group allowed the research team to attend meetings and ask for volunteers. Potential volunteers were told that research was being conducted with respect to memory deficits and head injury. Anyone who had sustained a head injury, and who experienced a problem with memory, qualified for initial testing. No financial reimbursement was offered. Tests would be conducted at a location and time convenient to the volunteer. Volunteers would be involved in a maximum of two separate testing sessions, conducted a week apart. The tests would be simple recognition tests; they would not be invasive or stressful. Each session would last about an hour. All test data would remain confidential, and upon request would be released to the volunteer at the conclusion of the study. All connection between the individuals' identities and their results would be destroyed at the conclusion of the research. It was emphasized that it was highly unlikely that any individual would receive direct personal benefit from participating in the study. 
Retrieval

The benefit to the individuals would be the knowledge that they participated in research which may contribute to an understanding of, and ultimately better treatment for, traumatic brain injury. Specifics regarding research hypotheses were not provided.

After several months it was necessary to shift recruitment efforts from the support group population to other sources. Many members of the support group were living in group homes for the severely impaired. The post-test qualification rate with these volunteers was very low (approximately 25\%). Subjects were sought who had reintegrated into the mainstream of life. Previous research indicated that TBI survivors who lived independently were more likely to have the kind of retrieval deficit targeted for the study (Meyers, Meyers, \& Lange, 1993). To locate such survivors, posters were hung at schools, hospitals, and veterans' organizations. Announcements were made in college classes. Professionals such as physiatrists, neuropsychologists, occupational therapists, and optometrists were contacted and asked to speak to their patients regarding the study, inviting them to participate. The need was communicated into the TBI community "word of mouth."

The various recruitment efforts resulted in a sample 
diverse in its functional level and severity of deficit. While all subjects included in the study demonstrated the retrieval deficit, that is, they qualified quantitatively according to the criteria specified, it is important to note that the earlier recruits tended to be lower functioning, while the latter recruits were so high functioning that some were undistinguishable from the general population until tested with instruments designed to uncover their deficits.

A total of 33 volunteers was pre-tested to select persons showing the pattern of scores for retrieval deficit. Test results for 16 met the criterion for inclusion in the study and subsequent post-testing. Reasons for exclusion were as follows: Thirteen demonstrated the wrong pattern of test results: that is, their results defined them as having a storage deficit. One was disqualified due to the inability to perceive the stimulus. One did not keep the post test appointment. one would not consent to being post-tested. One was intoxicated at the time of the post-test appointment. Characteristics of the 16 men and women who were post-tested, and therefore included in the study, were as follows: All subjects were Caucasian. Their ages ranged

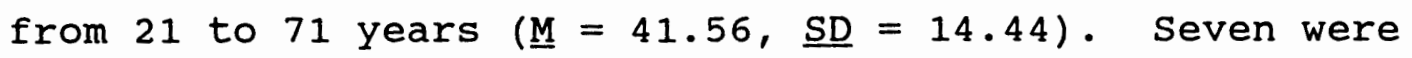


women, nine were men. Three were taking medication related to their head injury. The measurement for span of time since the trauma occurred was in months. The minimum was 4 months; the maximum was 791 months--almost 66 years $(\underline{M}=166.06$ months $[13.83$ years], $\underline{S D}=197.23)$. Number of days in coma ranged from 0 (four subjects reported not experiencing a coma) to 1 full year ( $\underline{M}=$ $34.81, \underline{S D}=91.23)$. Four people required assisted living environments. Five, at some point post-morbid, had engaged in a formal rehabilitation program. Education ranged from 12 to 20 years $(\underline{M}=15.25$, $\underline{\mathrm{SD}}=2.54)$. With respect to the nature of the trauma, one was a birth trauma, one was a cerebrovascular accident, 12 were impact-related, one was chemically induced, and one was the result of a sustained high fever (see Appendix 1). Materials

The Rey Osterrieth Complex Figure Test (CFT) (Rey, 1941; Osterrieth, 1944), shown in Appendix 2, was the stimulus. The direct copy procedure was used to measure individual ability to reproduce the figure. In this test, the subjects copy the figure while it is displayed before them, a behavior requiring complex higher order functioning (Lezak, 1983). This was the "Copy Test" in the experiment. Short-term recall was measured from a 
drawing of the CFT done from memory 3 minutes after initial exposure to the stimulus (3-minute delay). Longterm recall was measured from a drawing done from memory 30 minutes after initial exposure to the stimulus (30minute delay). The Recognition subtest (RS) for the CFT was used to measure recognition (see Appendix 3). Criteria for scoring the four tests were those outlined by Meyers \& Meyers (1992). Refer to Table 1 for interrater reliability information.

A list of descriptions of what the CFT might look like was used as both cues and mnemonics (see Appendix $4)$.

\section{Procedure}

Subjects were tested individually in the presence of either one or two experimenters. Prior to both testing sessions, they were asked to sign an informed consent form (see Appendix 5). The researcher read the form to the subjects, and answered any questions before requesting signatures.

The first testing session, the pre-test, was identical for all subjects. The Complex Figure was presented, and the subjects copied the figure, while it was displayed, using a \#2 pencil. They were allowed to erase. After the copy was completed, the Complex Figure 
Retrieval

and the copy were placed out of sight. Interference tests, taken from a protocol of standard neuropsychologic tests employed at Pacific Gateway Hospital in Portland, oregon, were administered for 3 minutes. The subjects were then asked to draw the Complex Figure from memory. After the 3-minute recall drawing was completed, it was removed from sight. Additional interference tests were administered for 30 minutes. The subjects were asked to draw the complex Figure from memory a second time. This copy was placed out of sight. The subjects were then presented with the CFT Recognition Subtest (RS), a series of drawings, some of which are part of the Complex Figure, and some of which are not. Those drawings recognized as being part of the original Complex Figure were to be circled by the subjects.

The copy score (COPY) was used to verify that the subjects could see and attend to the stimulus. The score from the 3-minute delay (SD) was used as a measure of short-term recall; the score from the 30-minute delay (LD) was used as a measure of long-term recall; the score from the Recognition subtest (RS) was used as a measure of recognition-memory.

Scores from the pre-test were used to establish the deficit pattern and subsequent inclusion in, or exclusion 
Retrieval

from, the post-test phase of the study. Criteria for exclusion were as follows:

1) The subject demonstrated normal memory.

Memory was considered normal if all four scores fell at or above the 25 th percentile of the distribution for non-head-injured persons. Therefore, pre-test scores were converted into percentiles, and compared to age-corrected norms (Meyers \& Meyers, 1992) (see Appendix 6).

2) The subject did not demonstrate a retrieval deficit pattern.

Retrieval deficit was defined by the relationship between the LD score and the RS score. Based on the research of Meyers, Meyers, \& Lange (1993), an RS score at or greater than 2 percentiles above an LD score constituted a pattern which was interpreted as representing a retrieval deficit. Because the Complex Figure Task and Recognition Subtest are scored with different scales, 2 percentiles difference can represent a large gap, dependent upon the norms used specific to the age, gender, and education of the subject. In our research, the smallest change from LD to RS was 2.5 percentiles. The raw scores for this subject represented $40 \%$ of a 
possible $100 \%$ (raw score 14.5 of a possible 36 total) for LD, and $79 \%$ (raw score 19 of a possible 24 total) for RS. An increase from LD to RS of $39 \%$ was considered sufficient to qualify as a retrieval deficit pattern.

Individuals who did not fit the desired profile were given an explanation of the outcome, thanked for their participation, and not tested further. Individuals who fit the profile were tested a second time 7 days after the first test. The second testing was the post-test. Subjects selected to continue were randomly assigned to one of four groups for the second series of tests, the post-test. The control group (CONTROL) received no treatment. The second administration of the CFT to CONTROL was identical to the first.

A second group (CUES) was read the list of cues (see Appendix 4) twice during testing; at the onset of both the 3-minute and 30-minute recall drawings. They were not read the list at the time of the copy test.

A third group (MNEM) was administered mnemonics at the time the subjects were looking at the CFT and copying it (the copy test). The experimenter read from the list of cues, and had the subject repeat back the descriptions of what the CFT might look like. For example, "it has a 
bowling ball", "a railroad track", "it looks like a rocket", and so forth. No further aids were presented to subjects in this group throughout the remainder of testing.

A fourth group (ВоTH) received a combination of the treatment for MNEM and the treatment for CUES.

Scores for the CFT Copy (COPY), 3-minute delay (SD), 30-minute delay (LD), and Recognition subtest (RS) for each of the 4 groups (TREATMENT) were recorded for the pre-test and post-test (TRIAL). 
Results

Means and standard deviations for COPY, SD, LD, and RS scores for the pre- and post-tests for the four experimental conditions are reported in Table 2.

Means of all scores increased from pre- to post-test except the COPY score of the BOTH condition. The greatest increase in scores from pre- to post-test for both SD and LD was observed in the BOTH condition. The smallest increase in scores from pre- to post-test for SD and LD was observed in CUES.

The highest overall variance for the SD and $\mathrm{LD}$ scores was observed in the pre- and post-tests for the CUES condition. Variance for those scores was also high in the BOTH condition.

COPY and RS scores remained stable across both trials and treatment conditions, with corresponding minimal variance.

A profile analysis of pre-test data was performed comparing the profile of scores for the four experimental conditions. No significant difference was found between profiles, $\underline{F}(9,36)=0.31, \underline{p}=.97$, confirming that variance among subjects was equally distributed across the four groups before administering the treatment. A multivariate analysis of variance (independent 
variables were TREATMENT [4 levels] and TRIAL [2 levels]; dependent variables were scores for COPY, SD, LD, and RS) was performed (see Table 3). Main effects for TRIAL were observed for $\mathrm{SD}, \underline{\mathrm{F}}(1,12)=18.69, \underline{\mathrm{p}}=.001 ; \mathrm{LD}, \underline{\mathrm{F}}(1,12)=$ $23.39, \underline{\mathrm{p}}<.001 ;$ and $\mathrm{RS}, \underline{\mathrm{F}}(1,12)=6.42, \underline{\mathrm{p}}=.03$. No main effects for TREATMENT were observed. There were no TRIAL bY TREATMENT interactions.

A profile analysis of post-test data comparing the profile of scores for the four experimental conditions showed no significant difference, $\mathrm{E}(9,36)=.23, \underline{\mathrm{p}}=.99$. The treatment conditions had no significant effect on the change between pre-test and post-test scores.

Power Analysis coefficients for TREATMENT for COPY, $S D, L D$, and RS were .35, .09, .08, and .15, respectively. Coefficients for TRIAL for the four scores were .21, .98, .99 , and .64, respectively (see Table 5). Results indicate the lack of TREATMENT effect could be the result of sample size.

\section{Post-Hoc Analyses}

The presence of the strong effect of TRIAL provided rationale for post hoc investigation.

While no TREATMENT effect was observed, and no interaction, follow-up $\underline{t}$ tests were performed to determine in what treatment groups, if any, were there 
differences in scores across trials. Differences were found between pre- and post-test SD scores for MNEM, $\underline{t}$ (3) $=-3.16, \underline{p}=.05$, and for $\mathrm{BOTH}, \underline{t}(3)=-4.89, \underline{p}=.016 ;$ and between pre- and post-test LD scores for MNEM, $\underline{t}(3)=$ $-3.37, \underline{p}=.043$, and for BOTH, $\underline{t}(3)=-5.70, \underline{p}=.011$ (see Table 4). The SD and LD scores for the MNEM and BOTH groups increased significantly from pre-test to post-test. The SD and ID scores for CONTROL and CUES did not change significantly from pre- to post-test. No RS scores changed significantly between trials.

A profile analysis which collapsed treatment conditions and compared the profile of all pre-test scores to that of all post-test scores revealed a main effect for TRIAL (change in scores from pre- to posttest), $\underline{F}(1,30)=6.97, \underline{Q}=.01$; a main effect for SCORE (differences between COPY, SD, LD, and RS scores), $\underline{F}(3,90)=105.07, \underline{p}<.001 ;$ and a TRIAL by SCORE interaction, $\underline{F}(3,90)=4.66, \underline{p}<.01$. The difference is significant in the profile of scores between the pre-test and post-test.

A multivariate analysis of variance was used to examine the relationship between LEVEL of function (HIGH and LOW) and TRIAL (change in scores from pre- to posttest) (see Table 7). Using the pre-test COPY score as 
the criterion for level of function (see Table 6 for Means and Standard Deviations), main effects for LEVEL were observed for $S D, \underline{E}(1,14)=5.01, \underline{p}=.04 ;$ and RS, $\underline{E}(1,14)=8.08, \underline{p}=.01$. Main effects for TRIAL were observed for $S D, \underline{F}(1,14)=18.55, \underline{p}=.001 ; L D, \underline{F}(1,14)=$ $24.49, \underline{\mathrm{p}}<.001 ;$ and $\mathrm{RS}, \underline{\mathrm{F}}(1,14)=6.61, \underline{\mathrm{p}}=.02 . \mathrm{A}$ LEVEL by TRIAL interaction occurred for COPY, $E(1,14)=$ $31.18, \mathrm{p}<.001$.

High functioning subjects scored higher than low functioning subjects across trials on SD and RS. Posttest scores were higher than pre-test scores for both HIGH and LOW functioning groups for SD, LD, and RS. Low functioning subjects scored lower than high functioning subjects on pre-test COPY scores, and higher than high functioning subjects on post-test copy scores.

Follow-up $t$ tests were performed. For the LEVEL effect, high functioning subjects scored significantly higher than low functioning subjects for the pre-test SD and RS scores, $\underline{t}(14)=-2.83, \underline{p}=.013$, and $\underline{t}(14)=-$ $2.41, \underline{p}=.03$, respectively. No significant difference was found in post-test scores (see Table 8).

For the TRIAL effect, post-test scores were significantly higher than pre-test scores for high functioning subjects for $S D, \underline{t}(7)=-2.74, \underline{p}=.029$; LD, 
Retrieval

$\underline{t}(7)=-2.40, \underline{p}=.048 ;$ and $\mathrm{RS}, \underline{t}(7)=-2.50, \underline{p}=.043$.

For low functioning subjects, post-test scores were

significantly higher than pre-test scores for SD, $t(7)$

$=-3.32, \underline{p}=.013 ;$ and $L D, \underline{t}(7)=-4.65, \underline{p}=.002$. No

significant difference occurred for RS for low

functioning subjects (see Table 8). 
Retrieval

Discussion

\section{overview}

The outcome of the power analysis suggests that the small sample size may be responsible for the lack of hypothesized results. A number of factors influenced the decision to terminate the project before obtaining more subjects: (1) Ethical parameters limited the ability of professionals to provide access to potential participants. (2) One full year of recruiting and testing yielded what is reported here. (3) The community of head injury survivors, upon whom this research depended, expressed their desire to support more qualitative research which does not use neuropsychological instruments. We offer the following interpretation of results recognizing the limitations imposed by the sample size.

The profile analysis of pre-test data showed no significant difference among groups, indicating our random assignment efforts worked and allowing us to proceed with our analysis.

The TRIAL by TREATMENT analysis of variance indicated that scores increased from pre- to post-test, but that the treatments had no significant effect on that increase. The profile analysis of post-test data 
confirmed there was no effect of TREATMENT.

As stated, a greater number of subjects may have allowed differences in the treatment groups to be expressed at a significant level. The power analysis indicates the inadequacy of the small sample size in all results except in the effect of TRIAL for tests involving recall (SD and $L D$ ). That is, the increase in SD and $L D$ scores from pre- to post-test is a robust result which would not be expected to be reversed were the sample larger.

\section{Testing of the Hypotheses}

1) For the CUES group, the SD and LD scores were expected to increase significantly from pre- to posttest. This result did not occur.

2) For the CUES group, the post-test SD and LD scores were expected to be significantly higher than the same scores for the CONTROL and MNEM groups. This result did not occur. In fact, the post-test SD and LD scores for CUES were the lowest of the four treatment groups. 3) None of the test scores for CONTROL was expected to change significantly from pre-test to post-test. This result did occur. However, there was no effect of TREATMENT for CUES, MNEM, or BOTH in the CONTROL group either. Without a larger sample, it is not possible to 
know whether CONTROL did not increase due to lack of treatment, or due to lack of power.

4) Scores for MNEM were not expected to change significantly from pre-test to post-test. scores for treatment groups did not change significantly across trials.

5) Because mnemonics were not expected to increase recall, post-test SD and LD scores for BOTH (BOTH includes mnemonics and cues) were not expected to be significantly different from those for CUES. Although, as predicted, no TREATMENT effect occurred, and therefore post-test SD and LD scores for BOTH were not significantly different from those for CUES, it must be noted that the difference in post-test means for SD and LD was the greatest between CUES and BOTH. The power analysis implies that with a larger sample, this difference might have been significant.

\section{Two Questions}

In this experiment the sample size was not large enough to allow for strong inferences about treatments. The lack of effect may be a result of sample size, of no effect of treatment, or of the effects of extraneous variables. However, although hypothesized results did not occur, a review of the results shows unexpected strong effects which warrant consideration. 
Retrieval

1) What happened in CUES? Contrary to prediction, scores did not increase significantly from pre- to posttest. Of more interest, the mean post-test CUES scores were not only lower than those for MNEM and BOTH, they were also lower than those for CONTROL, the group that received no treatment.

2) What happened in MNEM? The only significant increase in SD and LD scores from pre- to post-test was noted when mnemonics were used--in the MNEM and BOTH conditions.

To provide a basis for investigating these questions, the descriptive statistics will be considered. Means for all scores increased from pre- to posttest except the COPY score of the BOTH condition, which decreased slightly. This increase was expected. Although the subjects have memory deficits, they possess capacity for recall which varies between subjects and situations.

The relative stability of the COPY and RS scores was also anticipated. The COPY task does not specifically exercise recall. The RS task involves visual cues, and the subjects' near-normal scores on the RS pre-test (the mean fell at the 25 th percentile) is what qualified them for inclusion in the study. 
Cues. The greatest increase in SD and $L D$ means from pre- to post-test was observed in ВОTH. The smallest was observed in CUES. Also, CUES had the highest variance of the treatment groups. Variance for BOTH, which includes the treatment of cues, was also high.

The combination of (1) the increase in SD and LD means for pre- to post-test in CUES being smaller than that in CONTROL, and (2) the high variance in CUES, suggests the presence of something actively suppressing recall. In the CUES and BOTH conditions, cues were read to the subjects as they drew the CFT from recall at the 3-minute and 30-minute delays. It is possible that this verbal exchange acted as interference to recall, and became a distraction.

Distractibility is often observed among survivors of TBI; it accounts for adjustment problems and may be mistaken for other, more profound deficits (Lezak, 1983). Distraction becomes an "environmental hazard" to the head injured person. Coping and compensation often include active management of distraction.

During one testing session for this research project, the subject interrupted his task to replace the researcher's pencil with a felt-tipped pen. The noise of the pencil as the researcher took notes was so 
distracting to the subject it affected his ability to perform the task. The volunteers selected for the study were those who responded positively to the cues presented in the Recognition subtest during the pre-test. Their high RS score in relation to their low LD score was what qualified them for the study--what defined them as "retrieval deficit." However, the RS cues were visual, and silently presented.

Because these people responded to the RS cues, they were expected also to respond to the cues presented during the treatment. But the treatment cues were verbal, and may have been distracting. It is possible that presentation of verbal cues at the time when subjects were trying to recall the stimulus served to decrease, not increase, performance.

Mnemonics. Subjects were not expected to respond to mnemonics, because use of mnemonics is assumed to require retrieval capacity, and these subjects were selected for their lack of unaided retrieval capacity. Why, then, were their scores highest when mnemonics were used to enhance recall?

As noted in the discussion about subject selection, the overall group tended to be higher functioning, some having successfully reintegrated into normal life. While 
they presented a retrieval deficit, it may not have been as severe or clearly defined as may have been found with a lower functioning sample. Perhaps higher functioning TBI's are capable of making use of both mnemonics and cues.

The mnemonic device is thought to exercise depth of processing. The memory cue is repeated at some point prior to recall. The act of repetition is thought to "deepen the imprint" of the target stimulus into memory. Because the target stimulus is "processed deeply" it is expected to be more available for recall at some time in the future. This research assumed a clear distinction between usefulness of mnemonics and usefulness of cues; it assumed that the retrieval process must be intact in order for mnemonics to be useful. However, the pattern of results obtained here suggest that rather than needing retrieval to be able to use mnemonics, perhaps the use of mnemonics is an exercise which specifically acts on and renovates retrieval processes. This may be particularly true with higher functioning TBI's whose retrieval process is not utterly destroyed.

The overall improvement from pre- to post-test could be considered evidence of the positive effect of mnemonics with this group of retrieval deficit TBI's. It 
may be that the pre-test served as a mnemonic exercise for the post-test, accounting for the robust effect of TRIAL.

Given the small sample size and lack of significant effect of TREATMENT, consideration of the effect of mnemonics must remain speculation. What can be asserted with certainty, however, is that when treatment groups were combined and the overall pre-test profile was compared to that of the post-test, the difference in profiles was significant. The entire sample improved in performance with repeated exposure to the stimulus. A practice effect occurred.

Post-HoC Analyses Discussion

T tests were used to investigate the significant main effect of TRIAL in SD, LD, and RS. They indicated that there was a significant increase in SD and LD scores from pre- to post-test in MNEM and BOTH. SD and LD were the target scores. Of the four scores collected (COPY, $S D, L D$, and $R S), S D$ and $L D$ were the scores which involved active recall. The internal aid of mnemonics was used in the MNEM condition, and also in the BOTH condition. In the tests involving recall, then, mnemonics were used in both situations where a significant difference was found between pre- and post-test scores. In addition, the 
largest gap between post-test treatment score means existed between MNEM and BOTH in the SD and LD scores. This suggests that the combination of cues and mnemonics may be more useful in remediating memory deficits than either used alone.

High Vs. Low Function: Sohlberg and Mateer (1989) maintained that practice can increase recall when applied in the "process-specific" mode. What specific process, then, did this experiment isolate and exercise, that such a strong practice effect was observed?

To investigate that question, the sample was divided into two groups - high and low functioning. The criterion for the division was the pre-test COPY score. Because copying requires complex higher order functioning (Lezak, 1983), it was considered an appropriate measure of overall level of function. The group was divided evenly at the median; eight subjects with lower scores in the low functioning group (LOW); higher scores in the high functioning group ( $\mathrm{HIGH})$. The expectation was that scores for $\mathrm{HIGH}$ would be higher than those for LOW in all categories. In addition, we were interested to know if the HIGH and LOW groups would show different degrees of improvement across trials, indicating that either $\mathrm{HIGH}$ or LOW might respond more strongly to practice. From there 
Retrieval

the question could be asked, what are the characteristics of the group that responded more strongly to practice? Answers to these questions might lay the groundwork for consideration of the post-hoc question: What specific processes were exercised, that practice, with this group, served to increase recall?

A multivariate analysis of variance was performed to examine the relationship between level of function and the change in scores from pre- to post-test. A main effect of LEVEL occurred. HIGH scored higher than LOW in SD and RS. Higher functioning TBI's performed better than low on the test requiring short-term recall, but when using long-term recall, the two groups were equal. For long-term recall, the high vs. low distinction disappeared. Also, the higher functioning subjects performed better with the visual cues presented in RS. Follow-up $\underline{t}$ tests showed that HIGH scored higher on the pre-test SD and RS scores only; not on post-test scores. Repeated exposure (i.e., practice) appears to be another factor which equalizes the two functional groups.

A main effect of TRIAL was observed for SD, LD and RS, providing more evidence for an overall practice effect. Follow-up $t$ tests showed post-test scores were higher than pre-test scores only for the tests involving 
recall: $S D$ and $L D$.

Post-test scores for RS were higher than pre-test scores for the HIGH group, but not for the LOW. Again, performance on the visual cue task presented itself as a distinguishing feature between high and low functioning TBI's.

A LEVEL by TRIAL interaction occurred for COPY. LOW performed lower than HIGH on the pre-test COPY, but higher than HIGH on the post-test COPY. Of course, the former is a function of how the sample was divided. It is interesting, though, that the HIGH copy score decreased slightly across trials, while the Low copy score increased to be greater than that of HIGH by the post-test. The maximum score for the CFT is 36. While the mean for the entire sample fell below the 25 th percentile, it was relatively close to the maximum score for the present sample, indicating a ceiling effect may account for the leveling off of scores. Still, why the significant interaction?

COPY is not specifically a test of recall, although features of recall come into play. For instance, at the onset of the post-test, many subjects would see the CFT and remark, "Oh, this again!" They recalled the stimulus from the pre-test. Perhaps motivation became a factor. 
Higher functioning subjects may have lost interest by the post-test, while lower functioning subjects felt the need to prove that this time, they could do better.

In discussions held after completing data collection, participants shared their subjective experience of the protocol. Based on these discussions, the following speculations are offered: The pre-test protocol tends to strip subjects of any opportunity to use their private compensation methods. The CFT is shown to them, they draw it, then all evidence of the stimulus is removed. At that point, they are not aware they will be asked to recall the stimulus from memory. The request is a surprise. Had they known, they probably would have prepared mentally, possibly by using their own compensation methods developed over months and years of learning how to negotiate in everyday conditions of living (a "normal" world). So, particularly for the lower functioning group (people who must work harder at appearing normal) perhaps at the post-test they remembered the surprise from the pre-test; they were prepared, and they tried harder. This effort could then have paid off during COPY, when the stimulus was present, improving their performance. However, after the visual aid of the CFT was removed, although they knew they were 
going to have to recall the stimulus, their high motivation could not compensate for the lost cues of the CFT and the LOW performance again fell below that of HIGH.

Summary of the Post-Hoc Analyses: HIGH was expected to perform higher than LOW across tasks, and a TRIAL by LEVEL interaction was sought. The performance of $\mathrm{HIGH}$ was expected to increase with practice more than that of Low. What occurred was:

1) High functioning subjects performed better than low in tasks involving short-term memory.

2) High functioning subjects performed better than low in tasks involving visual cues.

3) Tasks requiring recall after 30 minutes equalized the two functional groups.

4) Practice, i.e., repeated exposure, equalized the two functional groups.

5) The combination of cues and mnemonics appears to be more effective in aiding recall than either when used alone.

The purpose of the post-hoc analysis was to see if practice helped one functional group more than the other. If differences were found, we could then turn to group demographics and associate characteristics with 
susceptibility to practice. But practice helped both groups equally.

As noted earlier, our sample was highly

heterogenous. One strong common characteristic, that which qualified subjects for the study, was presence of the retrieval deficit. The results of the post-hoc analysis suggest that for the retrieval deficit, practice--perhaps mediated by mnemonic aids--may be useful in aiding recall. The next step in research would be to gather a subject pool composed of the various deficits defined by Mateer and Sohlberg (attention, encoding, storage, and retrieval) and test them to search for differential response to practice.

Post-hoc results showed high functioning subjects performed higher than low functioning subjects on tasks involving short term memory and visual cues. One possible explanation is a more intact capacity for attention among higher functioning subjects. What characteristics affecting the capacity for attention differentiate HIGH from LOW?

Demographics of the Functional Groups: Information was collected regarding gender, age, medications, number of months since trauma, number of days in coma, assistedliving requirements, education, formal rehabilitation, 
Retrieval

and nature of trauma. of these demographic data, three categories clearly divide the two functional groups.

1) No subjects in the HIGH functioning group were receiving medications related to their head injury. Three of the eight in the LOW functioning group were receiving such medications.

2) Average time in coma was six days for HIGH, 63 days for LOW.

3) All subjects in HIGH lived independently. Four of the eight in LOW required assisted-living environments.

\section{Conclusion}

The success of community re-entry for survivors of TBI relies on appropriate diagnosis and rehabilitation efforts. Restoration of, or assistance to, functional memory is a key component of rehabilitation, and a common problem with TBI. The current task for TBI research is to make useful distinctions about memory systems and the compensation methods those systems, when damaged, might employ.

The intention of this project was to isolate people with the specific impairment of the retrieval process, and test them to find what might help them recall. Cues were expected to be a more powerful aid to memory than 
mnemonics. The opposite was demonstrated. In addition, practice was discovered to be the most potent influence in aiding recall with this sample and this design.

The five hypotheses have been discussed. Though inferences have been made based on trends in the data, the significant result remains the strong practice effect.

In the process and outcome of the experiment, highly qualitative influences have surfaced.

1) Combining information from the literature with our subjects' reports, we feel distraction affected the results.

2) Attention may account for differential performance on tasks involving short term memory and visual cues.

3) For lower functioning subjects, motivation for may account for their performing better than higher functioning subjects on the post-test COPY tasks.

4) There appears to be an association between the demographics of this group and the strong susceptibility to practice.

5) The characteristics associated with higher functioning subjects (and higher performance on short term memory tasks and visual cues) were (a) no medications, (b) shorter time in coma, and (c) 
independent living.

In considering future research, one alternative is to remain with the original quantitative model and pursue stronger experimental evidence about our hypotheses.

1) A greater number of subjects could be sought and tested with the current design, in order to know whether the results were a function of treatment or power of the applied statistical tests.

2) The design could be altered to incorporate presentation of visual, non-distracting cues in the CUES condition.

3) Subjects presenting the four patterns from the Sohlberg and Mateer taxonomy (attention, encoding, storage, retrieval) could be tested for differential response to practice.

4) Methods of analysis could be employed which are designed to construct a model associating performance with other factors.

A second and perhaps more appropriate alternative is to ask questions such as: What compensation methods do TBI survivors develop on their own? Do those methods generalize? How can they be enhanced? Can they be taught to others? If so, what is the best method of instruction? Then a research design could be constructed 
Retrieval

which examines compensation as opposed to deficits. The current design effectively strips subjects of any opportunity to use their private, perhaps unconscious, methods of compensation. It then measures their performance against normal data and reveals what is already obvious: they are not normal. Perhaps a more meaningful research project would be to gather qualitative data and develop an instrument which tests capacities that are meaningful in the lives of TBI survivors. 
References

Bohnen, N., Jolles, J., \& Twijnstra, A. (1992).

Neuropsychological deficits in patients with persistent symptoms six months after mild head injury.

Neurosurgery,

$\underline{30}(5), 692-696$.

Bowers, J. S., \& Schacter, D. L. (1990). Implicit memory and test awareness. Journal of Experimental Psychology: Learning Memory, and Cognition, 16(3), 404416 .

Brotherton, F. A., Thomas, L. L., Wisotzek, I. E., \& Milan, M. A. (1988). Social skills training in the rehabilitation of patients with traumatic closed head injury. Archives of Physical Medicine and Rehabilitation, 69, 827-832.

Cermak, L. S. Human Memory and Amnesia. Lawrence Erlbaum Associates, Hillsdale, NJ, 1982.

Cole, J. R., Cope, D. N., \& Cervelli, L. (1985). Rehabilitation of the severely brain-injured patient: A community-based, low-cost model program. Archives of Physical Medicine and Rehabilitation, 66, 38-40.

Craik, F. I., \& Lockhart, R. S. (1972). Levels of processing: A framework for memory research. Journal of Verbal Learning and Verbal Behavior, 11, 671-684. 
Craik, F. I., \& Watkins, M. H. (1973). The role of rehearsal in short-term memory. Journal of Verbal Learning and Verbal Behavior, 12, 599-607.

Elsass, L., \& Kinsella, G. (1987). Social interaction following severe closed head injury. Psychological Medicine, 17, 67-78.

Glasgow, R. E., Zeiss, M. B., \& Lewinsohn, P. M. (1977). Case studies on remediating memory deficits in brain-damaged individuals. Journal of Clinical Psychology, 33(4), 1049-1054.

Glisky, E., \& Schacter, D. (1986). Remediation of organic memory disorders: Current status and future prospects. Journal of Head Trauma Rehabilitation, $1(3)$, $54-63$.

Godfrey, H. , \& Knight, R. G. (1985). Cognitive rehabilitation of memory functioning in amnesic alcoholics. Journal of Consulting and Clinical Psychology, 43, 555-557.

Godfrey, H. P., Knight, R. G., Marsh, N. V., Moroney, B., \& Bishara, S. N. (1989). Social interaction and speed of information processing following very severe head-injury. Psychological Medicine, 19, 175-182.

Jones, M. K. (1974). Imagery as a mnemonic aid after left temporal lobectomy: Contrast between 
material-specific and generalized memory disorders. Neuropsychologia, 12, 21-30.

Klonoff, P. S., Snow, W. G., \& Costa, I. D. (1986). Quality of life in patients 2 to 4 years after closed head injury.

Kraus (1984). The incidence of acute brain injury and serious impairment in a defined population. American Journal of Epidemiology, $119(2)$,

Leland, M., Lewis, F. D., Hinman, S., \& Carrillo, R. (1988). Functional retraining of traumatically brain injured adults in a transdisciplinary environment. Rehabilitation Counseling Bulletin, 31, 289-297.

Levin, H. S., Matis, S., Ruff, R. M., Eisenberg, H. M., Marshall, L. F., Tabaddor, K., High, W. M., \& Frankowski, R. F. (1987). Neurobehavioral outcome following minor head injury: A three center study. Journal of Neurosurgery, 66, 234-243.

Lewinsohn, P. M., Danaher, B. G., \& Kikel, S. (1977). Visual imagery as a mnemonic aid for braininjured persons. Journal of Consulting and Clinical Psychology, 45 (5), 717-723.

Lezak, M. Neuropsychological Assessment. Oxford University Press, New York, 1983.

Life Initiatives Family Training, A Traumatic Brain 
Injury Training Manual for Families. Oregon Head Injury Foundation, 2nd ed., 1994.

Luria, A. R. Restoration of Brain Function After Brain Injury. MacMillan, New York, 1963.

Mateer, C. A., \& Sohlberg, M. M. Neuropsychological Studies of Nonfocal Brain Damage: Dementia and Trauma. Springer-Verlag, New York, 1988.

Meyers, J. E., \& Meyers, K. R. (1992). A Training Manual for the Clinical scoring of the Rey-Osterrieth Complex Figure and the Recognition Subtest (unpublished). Meyers, J. E., Meyers, K. R., \& Lange, D. (1993). Memory patterns for normals and brain injured subjects (unpublished).

National Head Injury Foundation. An Educator's

\section{Manua 1:}

What Educators Need to Know About students With Traumatic Head Injury. Framingham, MA, 1985.

Osterrieth, P. A. (1944). Le test de copie d'une figure complexe. Archives de Psychologie, 30, 206-356. Prigatano, G., Fordyce, D., Zeiner, H., Roueche, J., Pepping, M., \& Wood, B. (1984). Neuropsychological rehabilitation after closed head injury in young adults. Journal of Neurology, Neurosurgery, and Neuropsychiatry, 47, 505-513. 
Rey, A. (1941). L'examen psychologique dans les cas d'encephalopathie traumatique. Archives de Psychologie, $\underline{28}(112), 286-340$.

Ridley, B. (1989). Family response in head injury: Denial or hope for the future? Social science Medicine, $\underline{29}(4), 555-561$.

Schacter, D. L. (1992). Understanding implicit memory: A cognitive neuroscience approach. American Psychologist, $47(4), 559-569$.

Sohlberg, M. M., \& Mateer, C. A. Introduction to Cognitive Rehabilitation, Theory and Practice. The Guilford Press, New York, 1989.

Squire, L. R., \& Butters, N. Neuropsychology of Memory. Lawrence Erlbaum Associates, Hillsdale, NJ, 1984 .

Trexler, L. Neuropsychological Rehabilitation. The Guilford Press, New York, 1987.

Tulving, E., Hayman, C. A., \& Macdonald, C. A. (1991). Long-lasting perceptual priming and semantic learning in amnesia: A case experiment. Journal of Experimental Psychology: Learning, Memory, and Cognition, 17(4), 595-617.

Tulving, E. \& Schacter, D. L. (1990). Priming and human memory systems. Science, 247, 301-306. 
Retrieval

53

Walker, K. Clinical Methods - The History of the Physical and Laboratory Examination. Butterworth, Boston, 1976 .

Wehman, P., West, M., Fry, R., Sherron, P., Groah, C., Kreutzer, J., \& Sale, P. (1989). Effect of supported employment on the vocational outcomes of persons with traumatic brain injury. Journal of Applied Behavior Analysis, 22, 395-405. 
Retrieval

Table 1

Rey-Osterrieth Complex Figure Test

Inter-rater Reliability (Pearson's Correlation

Coefficient)

Rater 1

Rater 1

Rater 2

Rater 3
1

.938

.99
Rater 2

.938

1

.94
Rater 3

.99

.94

1 
Table 2

Means and Standard Deviations for Four Scores, Four Treatment conditions, and Two Trials

\begin{tabular}{|c|c|c|c|c|c|c|}
\hline & & & COPY & $\underline{\text { SD }}$ & $\underline{\underline{L D}}$ & $\underline{\mathrm{RS}}$ \\
\hline Pre-Test & $\underline{\mathbf{M}}$ & $=$ & 29.63 & 15.13 & 15.94 & 20.25 \\
\hline CONTROL & $\underline{S D}=$ & $=$ & 2.63 & 4.97 & 4.60 & .50 \\
\hline Post-Test & $\underline{\mathbf{M}}$ & $=$ & 31.38 & 20.13 & 20.69 & 21.00 \\
\hline CONTROL & $\underline{S D}$ & $=$ & 2.93 & 6.91 & 7.96 & 1.63 \\
\hline Pre-Test & $\underline{M}$ & $=$ & 30.44 & 16.69 & 16.31 & 20.25 \\
\hline CUES & $\underline{S D}$ & $=$ & 2.98 & 9.24 & 10.31 & .96 \\
\hline Post-Test & $\underline{\mathbf{M}}$ & $=$ & 31.75 & 19.19 & 20.19 & 20.75 \\
\hline CUES & $\underline{S D}$ & $=$ & 1.50 & 9.17 & 7.36 & .96 \\
\hline Pre-Test & $\underline{\mathrm{M}}$ & $=$ & 29.69 & 15.81 & 15.50 & 20.00 \\
\hline MNEMONICS & $\underline{S D}$ & $=$ & 2.27 & 2.86 & 1.31 & 1.41 \\
\hline Post-Test & $\underline{\mathbf{M}}$ & $=$ & 31.88 & 20.75 & 20.38 & 20.50 \\
\hline MNEMONICS & $\underline{S D}$ & $=$ & 1.11 & 1.40 & 1.80 & 1.00 \\
\hline Pre-Test & $\underline{\mathbf{M}}$ & $=$ & 32.88 & 15.81 & 14.56 & 20.25 \\
\hline BOTH & $\underline{S D}$ & $=$ & 2.55 & 6.97 & 6.86 & .50 \\
\hline Post-Test & $\underline{\mathbf{M}}$ & $=$ & 32.56 & 24.06 & 24.13 & 21.75 \\
\hline BOTH & $\underline{S D}$ & $=$ & 2.94 & 8.12 & 7.75 & .96 \\
\hline
\end{tabular}


Table 2 (Continued)

Means and Standard Deviations for Four Scores and Two Trials (Treatment conditions Combined)

\section{PRE-TEST}

COPY

SD

LD

$\underline{\mathrm{M}}=$

$\underline{\mathrm{SD}}=$

RS

$\underline{\mathrm{M}} \quad=$

$\underline{S D}=$
30.66

2.71

15.86

5.81

15.58

5.97

20.19

0.83
POST-TEST

31.89

2.08

21.03

6.60

21.34

6.24

21.00

1.16 
Retrieval

Table 3

Multivariate Analysis of Variance

\begin{tabular}{|c|c|c|c|c|c|}
\hline \multirow{3}{*}{ COPY } & & & REATMENT & TRIAL & TRIAL $\mathrm{x}$ TREATMENT \\
\hline & $\underline{F}(1,12)$ & $=$ & 1.83 & 1.60 & .31 \\
\hline & $\mathrm{p}=$ & & .20 & .23 & .82 \\
\hline \multirow[t]{2}{*}{$S D$} & $\underline{F}(1,12)$ & $=$ & .28 & 18.69 & .97 \\
\hline & $\underline{p}=$ & & .84 & .001 & .44 \\
\hline \multirow[t]{2}{*}{ LD } & $\underline{E}(1,12)$ & $=$ & .20 & 23.39 & 1.16 \\
\hline & $\underline{p}=$ & & .90 & .000 & .37 \\
\hline \multirow[t]{2}{*}{ RS } & $\underline{F}(1,12)$ & $=$ & .66 & 6.42 & .54 \\
\hline & $\underline{p}=$ & & .60 & .03 & .66 \\
\hline
\end{tabular}


Table 4

T tests for Main Effect of Trial

Pre- and Post-Test SD Scores

$\begin{array}{ll}\text { CONTROI } & \underline{t}(3)=-1.44, \underline{p}=.245 \\ \text { CUES } & \underline{t}(3)=-1.06, \underline{p}=.367 \\ \text { MNEM } & \underline{t}(3)=-3.16, \underline{p}=.051 \\ \text { BOTH } & \underline{t}(3)=-4.89, \underline{p}=.016\end{array}$

Pre- and Post-Test LD Scores

CONTROL

$\underline{t}(3)=-1.54, \underline{p}=.221$

CUES

$\underline{t}(3)=-1.34, \underline{p}=.272$

MNEM

$\underline{t}(3)=-3.37, \underline{p}=.043$

BOTH

$\underline{t}(3)=-5.70, \underline{p}=.011$

\section{Pre- and Post-Test RS Scores}

CONTROL

$\underline{t}(3)=-0.73, \underline{p}=.519$

CUES

$\underline{t}(3)=-1.73, \underline{p}=.182$

MNEM

$\underline{t}(3)=-1.73, \underline{p}=.182$

BOTH

$t(3)=-2.32, \underline{p}=.103$ 
Table 5

Power Analysis

Noncentrality

COPY

SD

LD

RS

Treatment

Trial

Interaction

1.97

6.42

1.63
5.49

1.59

.93

.84

.09

Trial

Interaction

Treatment

Trial

Interaction

.98

$$
2.92
$$$$
.20
$$

.35

.21

.09

$\begin{array}{rr}18.69 & .98 \\ 2.92 & .20\end{array}$

.59

.08

23.39

.99

3.49

.24

Power

.15

.64

.13 
Table 6

Means and Standard Deviations

Level of Function Specified by Pre-Test Copy Score

\begin{tabular}{|c|c|c|c|c|c|c|}
\hline & & & High Func & Eioning & Low Funct & oning \\
\hline & & & Pre-Test & Post-Test & Pre-Test & Post-Test \\
\hline COPY & $\underline{\mathbf{M}}$ & $=$ & 32.88 & 31.19 & 28.44 & 32.59 \\
\hline & $\underline{\mathrm{SD}}$ & $=$ & 1.36 & 2.53 & 1.62 & 1.32 \\
\hline SD & $\underline{\mathbf{M}}$ & $=$ & 19.25 & 23.34 & 12.47 & 18.72 \\
\hline & $\underline{S D}$ & $=$ & 5.82 & 5.99 & 3.48 & 6.72 \\
\hline$L D$ & $\underline{\mathbf{M}}$ & $=$ & 18.75 & 22.78 & 12.41 & 19.91 \\
\hline & $\underline{\mathrm{SD}}$ & $=$ & 6.38 & 5.98 & 3.56 & 6.55 \\
\hline RS & $\underline{\mathbf{M}}$ & $=$ & 20.63 & 21.50 & 19.75 & 20.50 \\
\hline & $\underline{S D}$ & $=$ & .74 & .76 & .71 & 1.31 \\
\hline
\end{tabular}


Retrieval

Table 7

Multivariate Analysis of Variance

Level of Function Specified by Pre-Test COPY Score

\begin{tabular}{|c|c|c|c|c|c|}
\hline & & & LEVEL & TRIAL & LEVEL $\times$ TRIAL \\
\hline \multirow[t]{2}{*}{ COPY } & $\underline{F}(1,14)$ & $=$ & 4.44 & 5.56 & 31.18 \\
\hline & $\underline{p}=$ & & .05 & .03 & .000 \\
\hline \multirow[t]{2}{*}{ SD } & $\underline{F}(1,14)$ & $=$ & 5.01 & 18.55 & .81 \\
\hline & $\underline{p}=$ & & .04 & .001 & .38 \\
\hline \multirow[t]{2}{*}{ LD } & $\underline{F}(1,14)$ & $=$ & 3.08 & 24.49 & 2.22 \\
\hline & $\underline{p}=$ & & .10 & .000 & .16 \\
\hline \multirow[t]{2}{*}{ RS } & $\underline{F}(1,14)$ & $=$ & 8.08 & 6.61 & .04 \\
\hline & $\underline{p}=$ & & .01 & .02 & .85 \\
\hline
\end{tabular}


Retrieval

Table 8

I tests for Effect of Trial and Effect of Level of Function (Level of Function specified by Pre-Test COPY Score)

Trial Effect

High Functioning

SD

$$
\underline{t}(7)=
$$$$
\underline{p}=
$$

LD $\underline{t}(7)=$

p $=$

RS $t(7)=$

$$
\underline{p}=
$$$$
-2.74
$$$$
.029
$$

.048

.043

$$
\begin{array}{r}
-3.32 \\
.013 \\
-4.65 \\
.002 \\
-1.45 \\
.197
\end{array}
$$

Low Functioning

Level Effect

$\begin{array}{llcc} & & \text { Pre-Test } & \text { Post-Test } \\ \text { SD } & \underline{t}(14)= & -2.83 & -1.45 \\ \underline{p}= & .013 & .168 \\ \text { RS } \underline{t}(14)= & -2.41 & -1.87 \\ \underline{p}= & .03 & .082\end{array}$


Appendix 1 .

GEAD INJURY RESEARCH PROJECT

Name:

Age:

Date of Birth:

Gender:

Education Level:

Race:

Occupation Prior to Injury:

Current occupation:

Date of Injury:

Nature of Injury:

Hemisphere Damage:

Handedness:

Length of Coma:

Current Medications:

Rancho Level:

Rehabilitation Programs:

Current Living Situation:

CFT SCORES:

Raw

Percentile

Time

Copy

3-Minute Delay

30-Minute Delay

Recognition

Interference Tests: 
APDENDIX 2.

Rey Dsterrieth Comolex Figure

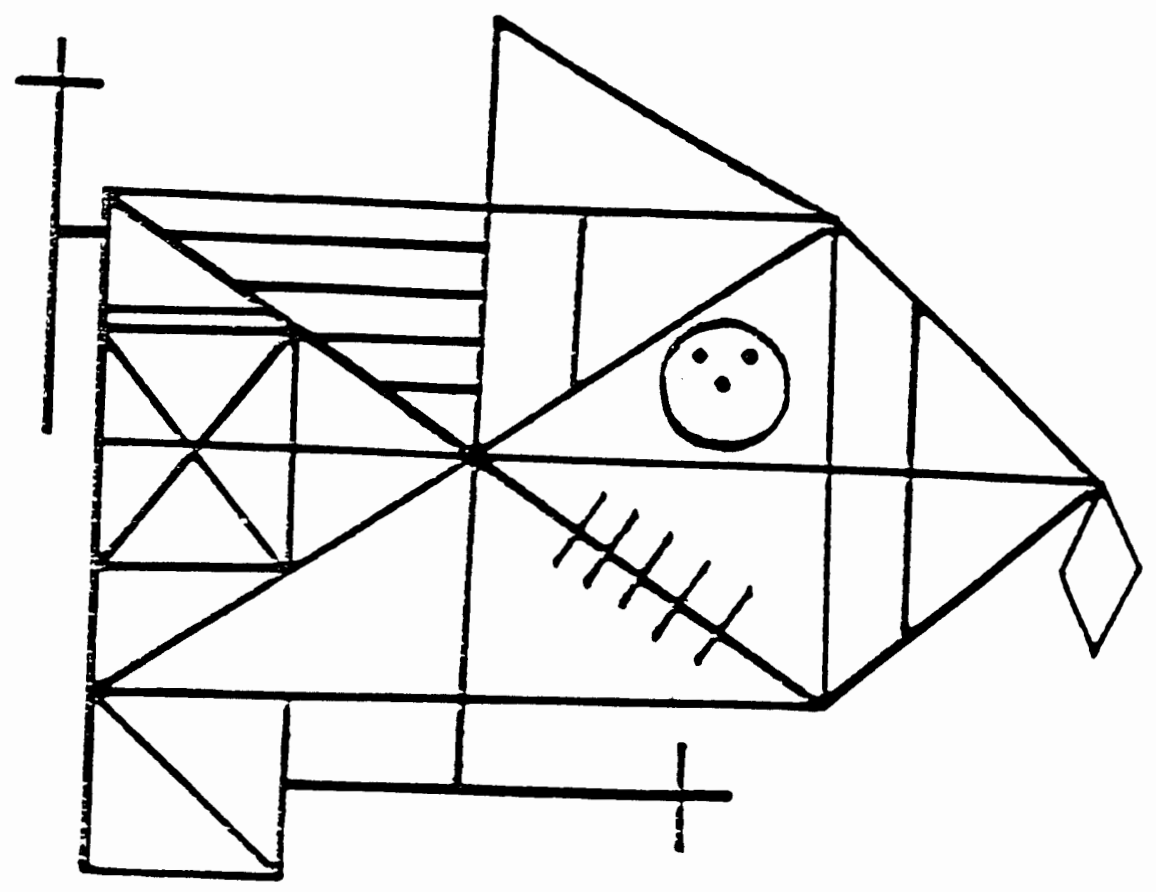




\section{Complex Figure: Recognition Subtest}

Name:

Date:

Age:

Sex: M F

Handedness: R L

Education:

\section{Directions:}

Circle the figures that were part of the larger whole design you copied and then drew. Each figure is facing the same direction as in the original design. There are four pages.

Turn the page and begin.

(Do aot write betow this tine)

Notes and Observadions:

False Positive:

Faise Negative:

Correct:

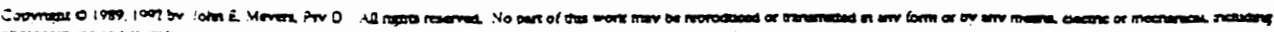

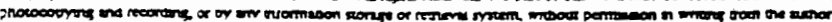


PAGE :
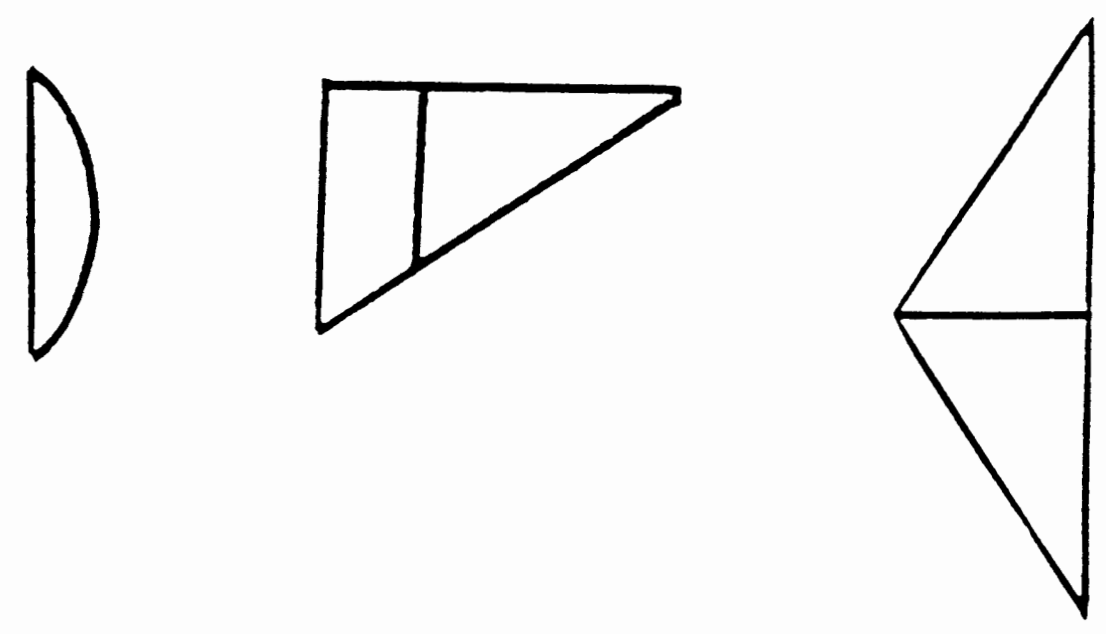

*

$\because$
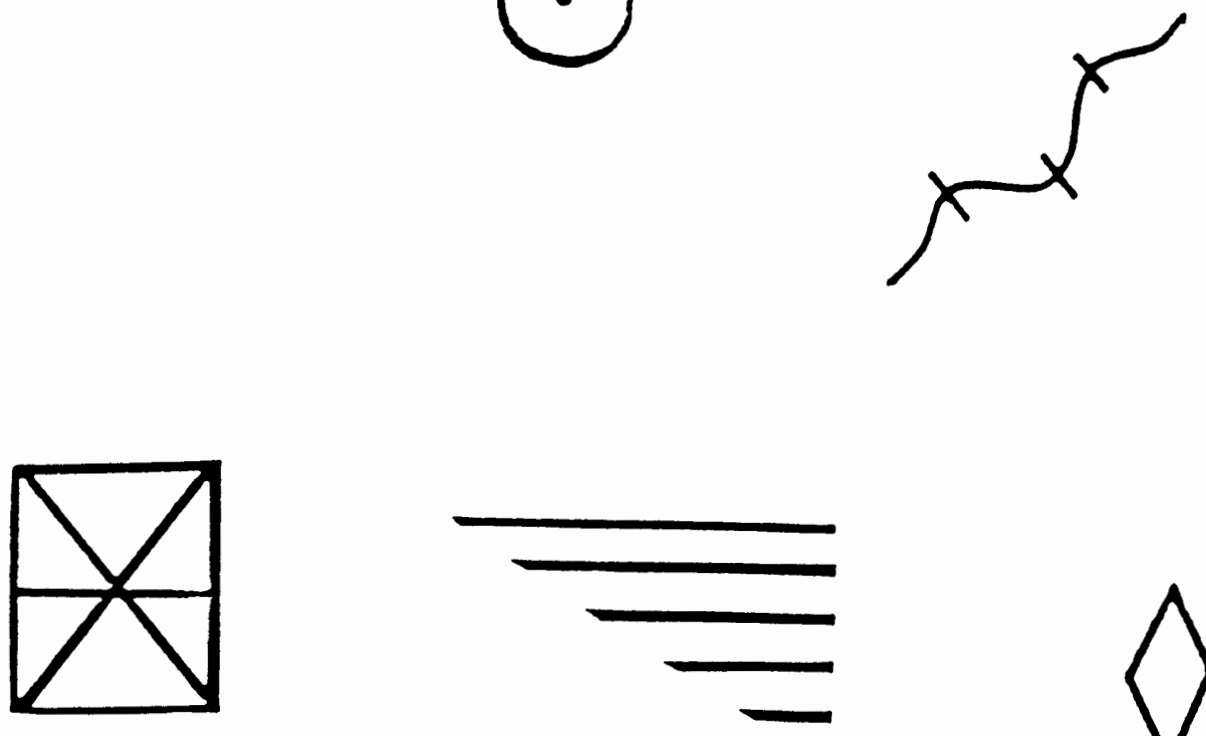

$\diamond$ 
PAGE 2
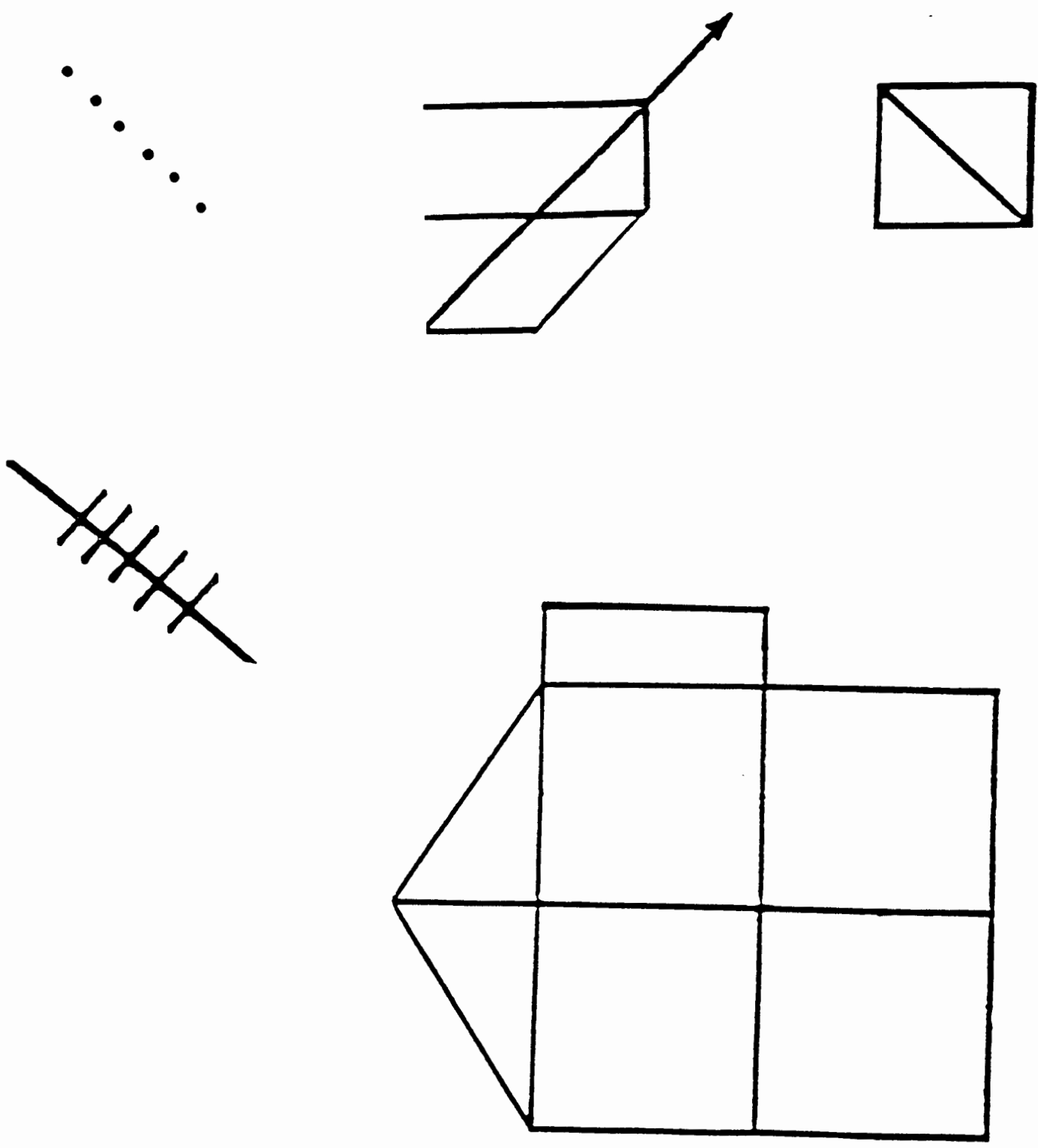
PAGE 3
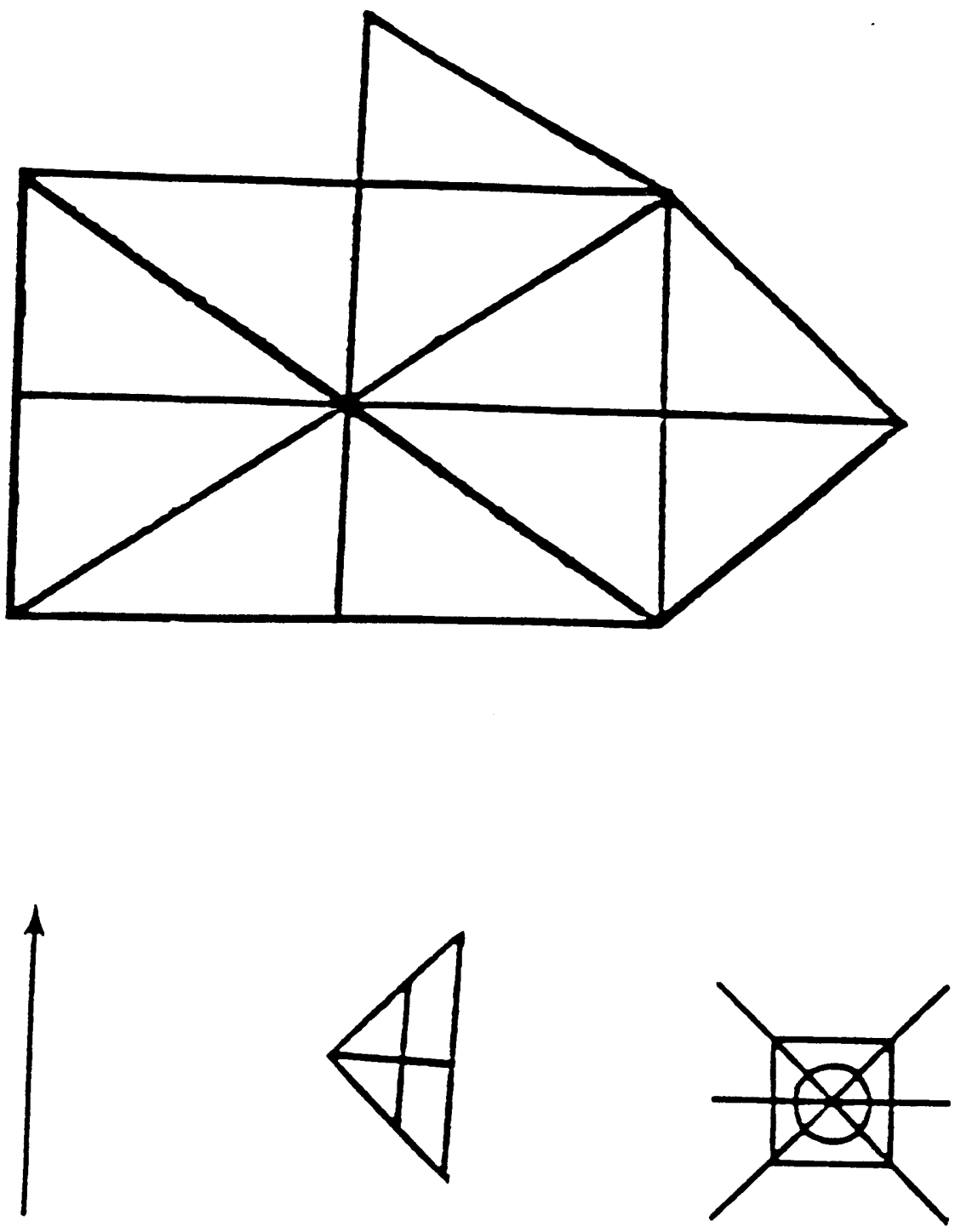

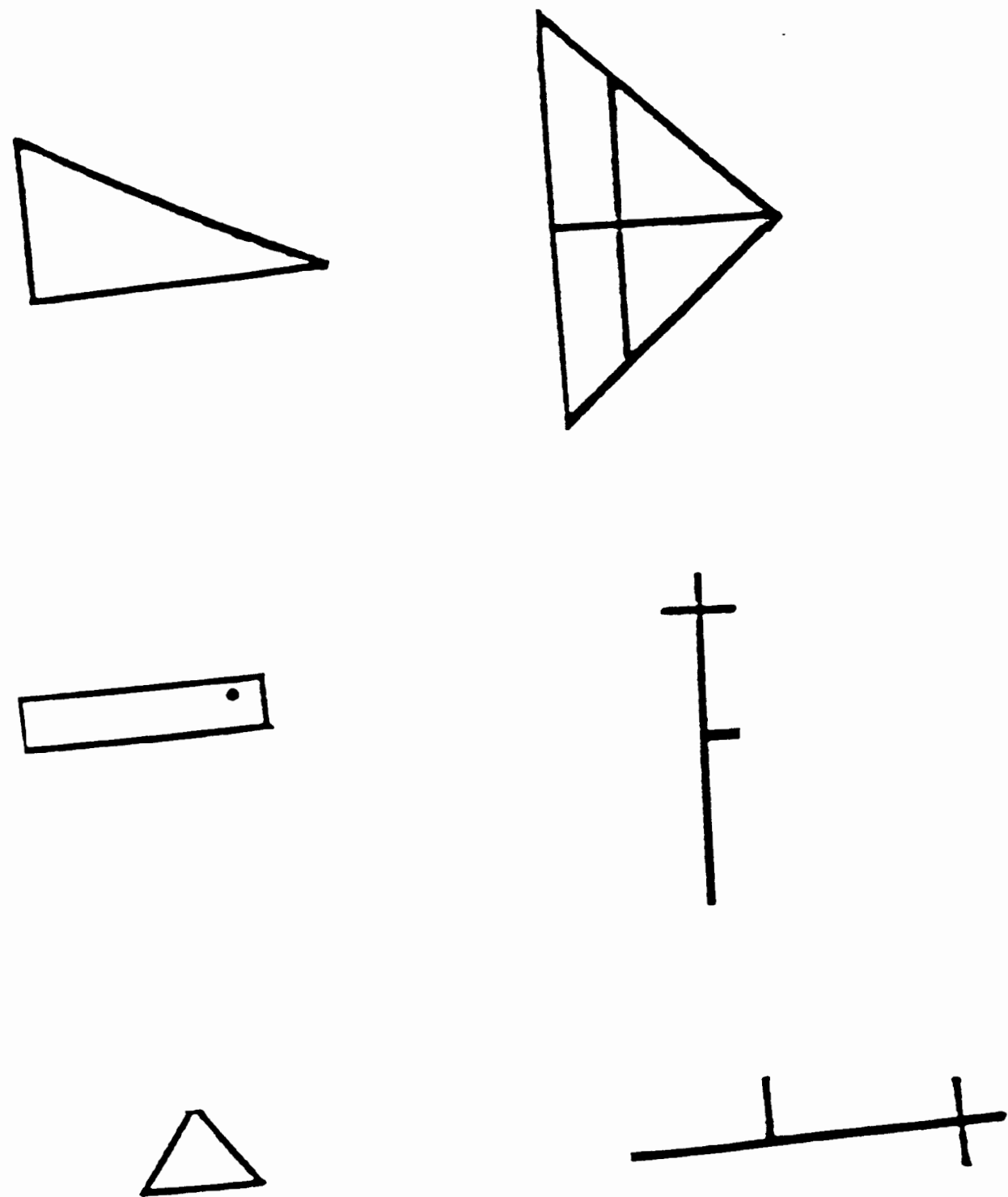
APPENDIX 4.

Description of Complex Figure for Cue and Mnemonic Aids

1. It's a rectangle with a triangle at the right end, and a triangle on top.

2. At the tip of the triangle on the right is a little diamondshaped figure.

3. It has two crosses; one on the left side, and one on the bottom.

4. It has a bowling ball in it.

5. It has something that looks like railroad tracks in it.

6. It has a box with an $x$ on the left side. 


\section{INEORMED CONSENT}

I, agree to take part in this research project on the study of memory loss among people with brain injury.

I understand that I will spend about an hour taking tests that will measure my ability to recall things.

I understand that I may become fatigued during the tests, and that I may not be able to do all of the tests accurately or compietely. has told me that the purpose of the study is to learn more about memory loss with head injured people, so that better rehabilitation can be designed for people with this problem.

I may not receive any direct benefit from taking part in this study. But the study may help to increase knowledge that may heip others in the future.

has offered to answer any questions I have about the study and what I am expected to do. has promised that all information I give will be kept confidential to the extent permitted by law, and that the names of all people in the study will be kept confidential.

I understand that I do not have to take part in this study, that I can withdraw from this study at any time, and that neither action will result in any effect or harm to me or my relationsinip with

(Name of home, institution, etc.)

I have read and understand the above information and agree to take part in this study.

Date: Signa ture :

Date : Signature: contact the Chair of the Human Subjects Research Review nommitos nffico nf rmante and Contracts. 105 Neuberder Hal: 
APPENDIX 6

Manual for the Rey-Osterrieth Complex Figure and Recognition Subtest

\section{CFT and Recognition Subtest \\ Females Age 16-39 years with 8-15 years Education

$$
(\mathrm{N}=93)
$$

\section{Copy Time (minutes) Three Minute Recall Thirty Minute Recall False Positive}

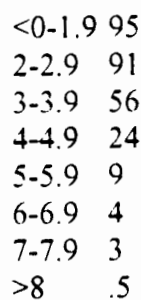

$\frac{\text { Copy Raw }}{<28.5}$

$28 \quad 1$

$28.5 \quad 1$

29

29.51

$30 \quad 1$

30.51

$31 \quad 1$

$31.5 \quad 1$

$32 \quad 3$

32.54

339

33.59

$34 \quad 16$

$34.5 \quad 16$

$\begin{array}{ll}35 & 37\end{array}$

$35.5 \quad 49$

$36 \quad 62$
$<19 \quad .5$

$19 \quad 1$

19.53

$20 \quad 6$

$20.5 \quad 8$

$21 \quad 10$

$21.5 \quad 11$

$22 \quad 13$

$22.5 \quad 16$

$23 \quad 19$

$23.5 \quad 22$

$24 \quad 26$

$24.5 \quad 31$

$25 \quad 36$

25.541

$26 \quad 46$

$26.5 \quad 50$

$27 \quad 55$

$27.5 \quad 58$

$28 \quad 61$

$28.5 \quad 65$

$29 \quad 69$

$29.5 \quad 74$

$30 \quad 80$

$30.5 \quad 81$

$31 \quad 82$

31.585

$32 \quad 87$

$32.5 \quad 88$

3390

$33.5 \quad 92$

$34 \quad 95$

$34.5 \quad 95$

$35 \quad 96$

$35.5 \quad 97$

$36 \quad 99$

$\begin{array}{llll}18 & .5 & 0 & 78 \\ 18.5 & 1 & 1 & 12 \\ 19 & 2 & 2 & 7 \\ 19.5 & 4 & 3 & 1 \\ 20 & 7 & >3 & .5\end{array}$

20.59

$21 \quad 11$

$21.5 \quad 13$

$22 \quad 15$

$22.5 \quad 16$

$23 \quad 18$

$23.5 \quad 20$

$24 \quad 23$

$24.5 \quad 26$

$25 \quad 30$

$25.5 \quad 35$

$26 \quad 41$

$26.5 \quad 46$

$27 \quad 52$

$27.5 \quad 53$

$28 \quad 55$

$28.5 \quad 60$

$29 \quad 65$

$29.5 \quad 70$

$30 \quad 75$

$30.5 \quad 78$

$31 \quad 81$

$31.5 \quad 82$

$32 \quad 83$

$32.5 \quad 85$

$33 \quad 88$

33.591

$34 \quad 95$

$34.5 \quad 96$

$35 \quad 97$

$35.5 \quad 98$

$36 \quad 99$

\section{Faise Negative}

$0 \quad 80$

$1 \quad 58$

236

320

46

$5 \quad 1$

$>5 \quad .5$

Correct

$<18 \quad .5$

$18 \quad 1$

$19 \quad 10$

$20 \quad 24$

$21 \quad 43$

$22 \quad 67$

$23 \quad 86$

$24 \quad 99$ 
Manual for the Rey-Osterrieth Complex Figure and Recognition Subtest

\section{CFT and Recognition Subtest}

Females Age 16-39 years with 16+ years Education

$$
(\mathrm{N}=32)
$$

Cupy Time (minutes) Three Minute Recall Thirty Minute Recall False Positive

$<0-1.995$

$2-2.9 \quad 43$

$3-3.9 \quad 21$

$4-4.9 \quad 12$

$5-5.97$

$6-6.9+$

$7-7.9 \quad 2$

$>8 \quad .5$

$\frac{\text { Copy Raw }}{<28 \quad .5}$

$28 \quad 1$

28.5

$29 \quad 1$

$29.5 \quad 1$

$30 \quad 1$

$305 \quad 1$

31

31.51

323

32.54

$33 \quad 9$

33.59

$34 \quad 21$

$34.5 \quad 16$

$35 \quad 25$

$35.5 \quad 49$

$36 \quad 62$
$<19 \quad .5$

$19 \quad 1$

19.52

$20 \quad 2$

$20.5 \quad 3$

$21 \quad 3$

$21.5 \quad 31$

$22 \quad 3$

22.56

239

$23.5 \quad 15$

$24 \quad 21$

$24.5 \quad 26$

$25 \quad 31$

$25.5 \quad 37$

$26 \quad 43$

$26.5 \quad 50$

$27 \quad 56$

$27.5 \quad 60$

$28 \quad 65$

$28.5 \quad 70$

$29 \quad 75$

$29.5 \quad 76$

$30 \quad 78$

$30.5 \quad 82$

$\begin{array}{ll}31 & 87\end{array}$

$\begin{array}{ll}31.5 & 91\end{array}$

$32 \quad 96$

$32.5 \quad 96$

3396

33.596

$34 \quad 97$

34.598

$35 \quad 99$

35.599

$36 \quad 99$

$\begin{array}{llll}18 & .5 & 0 & 71 \\ 18.5 & 1 & 1 & 15 \\ 19 & 2 & 2 & 5 \\ 19.5 & 4 & 3 & 1 \\ 20 & 7 & >3 & .5\end{array}$

20.59

213

21.56

229

$22.5 \quad 16$

$23 \quad 18$

$23.5 \quad 26$

$24 \quad 34$

$24.5 \quad 43$

$25 \quad 53$

$25.5 \quad 55$

$26 \quad 57$

$26.5 \quad 59$

$27 \quad 62$

$27.5 \quad 66$

$28 \quad 70$

$28.5 \quad 74$

$29 \quad 78$

$29.5 \quad 82$

$\begin{array}{ll}30 & 87\end{array}$

$30.5 \quad 78$

$31 \quad 90$

$31.5 \quad 92$

$32 \quad 93$

$32.5 \quad 93$

$33 \quad 96$

33.596

$34 \quad 96$

$34.5 \quad 96$

$\begin{array}{ll}35 & 97\end{array}$

$35.5 \quad 98$

$36 \quad 99$
False Negative

$\begin{array}{ll}0 & 87 \\ 1 & 68 \\ 2 & 34 \\ 3 & 12 \\ 4 & 4 \\ 5 & 1 \\ >5 & .5\end{array}$

Correct

$<18 \quad .5$

$18 \quad 1$

$19 \quad 6$

$20 \quad 18$

$21 \quad 43$

$22 \quad 81$

$23 \quad 93$

$24 \quad 99$ 
Manual for the Rey-Osterrieth Complex Figure and Recognition Subtest

CFT and Recognition Subtest

Males Age 16-39 years with 8-15 years Educatio::

$(\mathrm{N}=89)$

Copy Time (minutes) Three Minute Recall Thirty Minute Recall False Positive

\begin{tabular}{|c|c|c|c|c|c|c|c|}
\hline & \multirow{2}{*}{$\begin{array}{l}<20 \\
20\end{array}$} & \multirow{2}{*}{.5} & \multirow{2}{*}{$\begin{array}{l}<19 \\
19\end{array}$} & \multirow{2}{*}{.5} & \multirow{2}{*}{0} & 59 \\
\hline \multicolumn{2}{|c|}{$\begin{array}{ll}<0-1.995 \\
2-2.9 \quad 81\end{array}$} & & & & & & 7 \\
\hline \multicolumn{2}{|c|}{$\begin{array}{ll}2-2.9 & 81 \\
3-3.9 & 50\end{array}$} & 20.5 & 2 & 19.5 & 1 & 2 & 4 \\
\hline \multirow{2}{*}{$\begin{array}{l}4-4.9 \\
5-5.9\end{array}$} & 18 & 21 & 3 & 20 & 1 & 3 & 1 \\
\hline & 3 & 21.5 & 6 & 20.5 & 1.5 & \multirow[t]{2}{*}{$>3$} & \multirow[t]{2}{*}{.5} \\
\hline \multicolumn{2}{|c|}{$\begin{array}{ll}3-5.9 & 3 \\
6-6.9 & 1\end{array}$} & 22 & 8 & 21 & 2 & & \\
\hline \multirow[t]{2}{*}{$>6$} & .5 & 22.5 & 11 & 21.5 & 4 & \multirow{2}{*}{\multicolumn{2}{|c|}{ False Negative }} \\
\hline & & 23 & 15 & 22 & 7 & & \\
\hline & 23.5 & 18 & 22.5 & 9 & \multirow{2}{*}{$\begin{array}{l}0 \\
1\end{array}$} & \multirow{2}{*}{$\begin{array}{l}83 \\
62\end{array}$} \\
\hline \multicolumn{2}{|c|}{$\frac{\text { Copy Raw }}{528}$} & 24 & 22 & 23 & 12 & & \\
\hline 28 & 1 & 24.5 & 23 & 23.5 & 15 & 2 & 31 \\
\hline & 1 & 25 & 25 & 24 & 19 & 3 & 13 \\
\hline 29 & 2 & 25.5 & 29 & 24.5 & 23 & 4 & 2 \\
\hline 29.5 & 3 & 26 & 3.3 & 25 & 28 & 5 & 2 \\
\hline 30 & 3 & 26.5 & 37 & 25.5 & 31 & 6 & 1 \\
\hline 30.5 & 3 & 27 & 42 & 26 & 34 & 7 & .5 \\
\hline 31 & 4 & 27.5 & 48 & 26.5 & 41 & & \\
\hline 31.5 & 4 & 28 & 55 & 27 & 48 & \multicolumn{2}{|c|}{ Correct } \\
\hline 32 & 5 & 28.5 & 62 & 27.5 & 52 & $<18$ & .5 \\
\hline 32.5 & 5.5 & 29 & 69 & 28 & 57 & 18 & 1 \\
\hline 33 & 7 & 29.5 & 72 & 28.5 & 63 & 19 & 3 \\
\hline 33.5 & 8 & 30 & 75 & 29 & 70 & 20 & 24 \\
\hline 34 & 13 & 30.5 & 79 & 29.5 & 73 & 21 & 41 \\
\hline 34.5 & 13 & 31 & 83 & 30 & 76 & 22 & 75 \\
\hline 35 & 29 & 31.5 & 86 & 30.5 & 79 & 23 & 94 \\
\hline 35.5 & 29 & 32 & 89 & 31 & 82 & 24 & 99 \\
\hline \multirow[t]{10}{*}{36} & 70 & 32.5 & 91 & 31.5 & 83 & & \\
\hline & & 33 & 94 & 32 & 84 & & \\
\hline & & 33.5 & 95 & 32.5 & 88 & & \\
\hline & & 34 & 96 & 33 & 92 & & \\
\hline & & 34.5 & 96 & 33.5 & 93 & & \\
\hline & & 35 & 97 & 34 & 94 & & \\
\hline & & 35.5 & 98 & 34.5 & 95 & & \\
\hline & & 36 & 99 & 35 & 96 & & \\
\hline & & & & 35.5 & 98 & & \\
\hline & & & & 36 & 99 & & \\
\hline
\end{tabular}


Manual for the Rey-Osterrieth Complex Figure and Recognition Subtest

$$
\begin{aligned}
& \text { CFT and Recognition Subtest } \\
& \text { Males Age 16-39 years with 16+ years Education } \\
& (\mathrm{N}=30)
\end{aligned}
$$

\section{Copy Time (minutes) Three Minute Recall Thirty Minute Recall False Positive}

$$
\begin{array}{ll}
<0-1.9 & 97 \\
2-2.9 & 42 \\
3-3.9 & 14 \\
4-4.9 & 10 \\
5-5.9 & 4 \\
6-6.9 & 4 \\
7-7.9 & 2 \\
>8 & .5
\end{array}
$$

Copy Raw

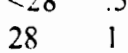

28.51

$29 \quad 1$

29.5

$30 \quad 1$

$30.5 \quad 1$

$31 \quad 3$

$31.5 \quad 5$

$32 \quad 7$

$32.5 \quad 7$

$33 \quad 7$

33.58

$34 \quad 10$

$34.5 \quad 19$

$35 \quad 28$

$35.5 \quad 50$

$36 \quad 71$

$21 \quad 7$ $\begin{array}{ll}0 & 89 \\ 1 & 4 \\ 2 & 2 \\ 3 & 1 \\ >3 & .5\end{array}$

False Negative

$0 \quad 92$

$1 \quad 67$

246

310

44

$\begin{array}{ll}5 & 1 \\ >5 & 5\end{array}$

Correct

$<17 \quad .5$

$17 \quad 1$

$18 \quad 3$

$19 \quad 3$

$20 \quad 10$

$21 \quad 46$

$22 \quad 75$

$23 \quad 96$

$24 \quad 99$
$<19 \quad .5$

$19 \quad 1$

19.53

$20 \quad 7$

$20.5 \quad 7$

$21.5 \quad 10$

$22 \quad 14$

$22.5 \quad 15$

$\begin{array}{ll}23 & 17\end{array}$

$23.5 \quad 21$

$24 \quad 25$

$24.5 \quad 25$

$25 \quad 25$

$25.5 \quad 32$

$26 \quad 39$

$\begin{array}{ll}26.5 & 42\end{array}$

$27 \quad 46$

$27.5 \quad 48$

$28 \quad 50$

$28.5 \quad 55$

$29 \quad 60$

$29.5 \quad 62$

$30 \quad 64$

$30.5 \quad 69$

$31 \quad 75$

31.580

$32 \quad 85$

32.590

$33 \quad 96$

$33.5 \quad 96$

$34 \quad 96$

$34.5 \quad 96$

$35 \quad 97$

$\begin{array}{ll}35.5 & 97\end{array}$

$36 \quad 99$

$19 \quad 1$

19.52

203

$20.5 \quad 3$

213

21.53

227

$\begin{array}{ll}22.5 & 10\end{array}$

$23 \quad 14$

$23.5 \quad 15$

$24 \quad 17$

$24.5 \quad 19$

$25 \quad 21$

$25.5 \quad 24$

$26 \quad 28$

$26.5 \quad 31$

$27 \quad 35$

$27.5 \quad 42$

$28 \quad 50$

$28.5 \quad 51$

$29 \quad 53$

$29.5 \quad 58$

$30 \quad 64$

$30.5 \quad 67$

$31 \quad 71$

$31.5 \quad 80$

$32 \quad 89$

32.590

$33 \quad 92$

$33.5 \quad 92$

$34 \quad 92$

$34.5 \quad 96$

$35 \quad 97$

35.598

$36 \quad 99$ 


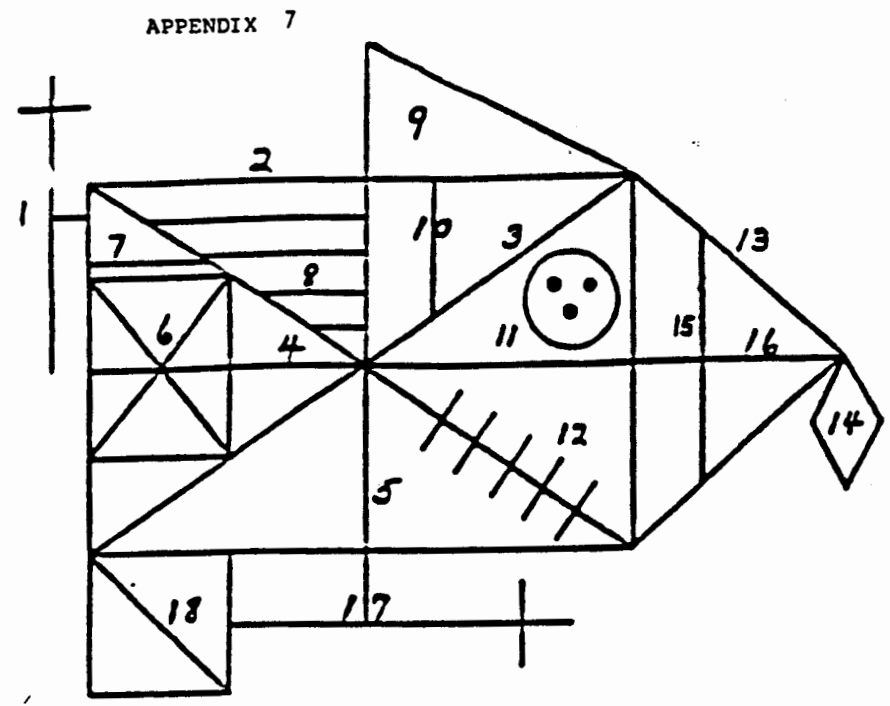

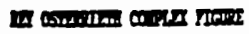

b

and

4

$\sin 1$

sin

Y' bing teail ain

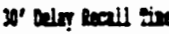

$\cos \operatorname{sen}$

y beln bor soure

201 Delọ Ex Sem

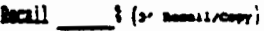

mosting

12. 2 .

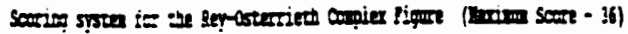
r noms

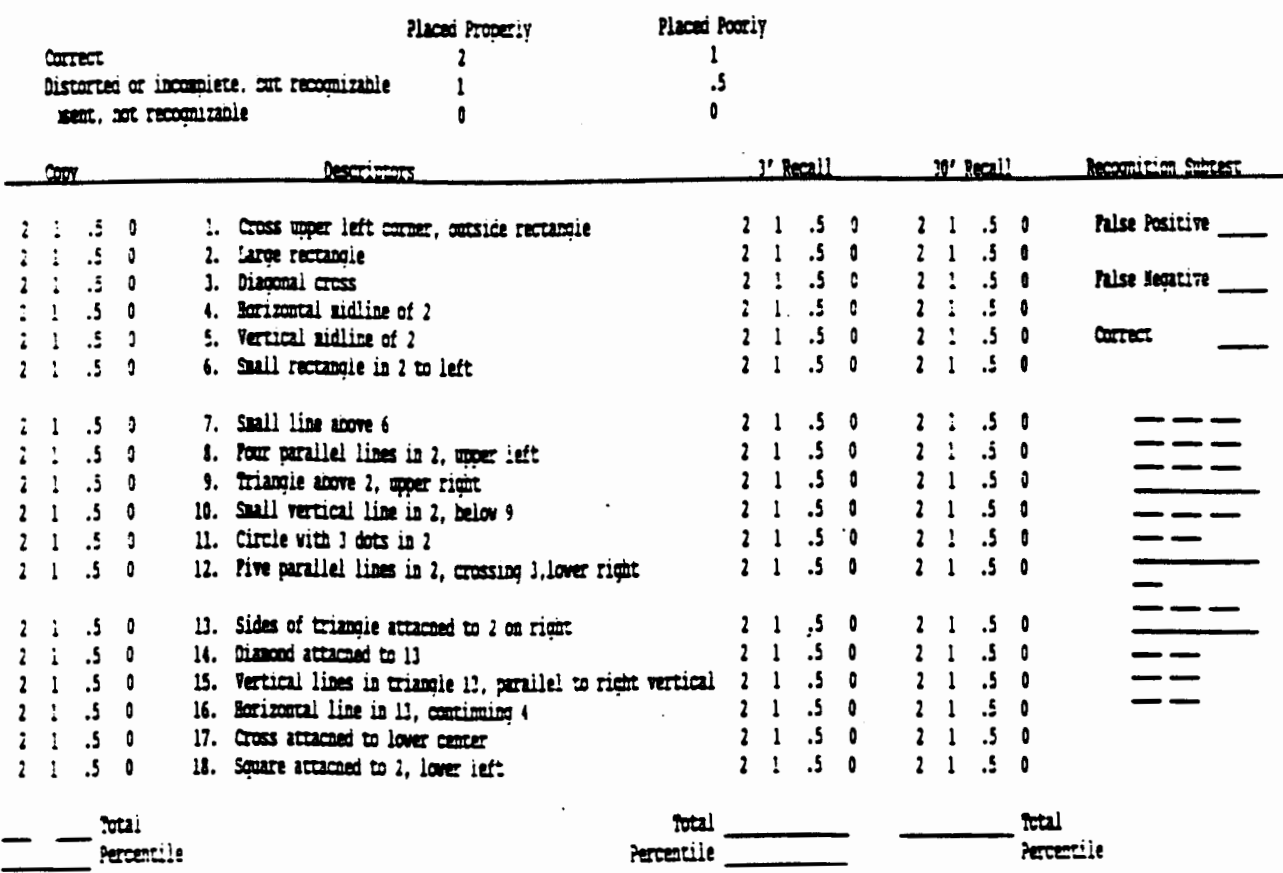

